\title{
Assessing uncertainties in global cropland futures using a conditional probabilistic modelling framework
}

\author{
Kerstin Engström $^{1}$, Stefan Olin ${ }^{1}$, Mark D. A. Rounsevell ${ }^{2}$, Sara Brogaard ${ }^{3}$, Detlef P. van Vuuren ${ }^{4,5}$, \\ Peter Alexander $^{2}$, Dave Murray-Rust ${ }^{6}$, and Almut Arneth ${ }^{7}$ \\ ${ }^{1}$ Department of Physical Geography and Ecosystem Science, Lund University, Sölvegatan 12, \\ 22362 Lund, Sweden \\ ${ }^{2}$ School of GeoSciences, University of Edinburgh, Geography Building, Drummond Street, \\ Edinburgh, EH89XP, UK \\ ${ }^{3}$ Centre for Sustainability Studies, Lund University (LUCSUS), Biskopsgatan 5, 22362 Lund, Sweden \\ ${ }^{4}$ PBL Netherlands Environmental Assessment Agency, Postbus 303, 3720 AH Bilthoven, the Netherlands \\ ${ }^{5}$ Copernicus Institute for Sustainable Development, Faculty of Geosciences, Utrecht University, \\ Heidelberglaan 2, 3584 CS Utrecht, the Netherlands \\ ${ }^{6}$ School of Informatics, University of Edinburgh Appleton Tower, 11 Crichton Street, Edinburgh, EH8 9LE, UK \\ ${ }^{7}$ Karlsruhe Institute of Technology, Institute of Meteorology and Climate Research, Atmospheric \\ Environmental Research (IMK-IFU), Kreuzeckbahnstr. 19, 82467 Garmisch-Partenkirchen, Germany
}

Correspondence to: Stefan Olin (stefan.olin@nateko.lu.se)

Received: 25 February 2016 - Published in Earth Syst. Dynam. Discuss.: 15 March 2016
Revised: 16 August 2016 - Accepted: 6 September 2016 - Published: 17 November 2016

Abstract. We present a modelling framework to simulate probabilistic futures of global cropland areas that are conditional on the SSP (shared socio-economic pathway) scenarios. Simulations are based on the Parsimonious Land Use Model (PLUM) linked with the global dynamic vegetation model LPJ-GUESS (Lund-Potsdam-Jena General Ecosystem Simulator) using socio-economic data from the SSPs and climate data from the RCPs (representative concentration pathways). The simulated range of global cropland is $893-2380$ Mha in 2100 ( \pm 1 standard deviation), with the main uncertainties arising from differences in the socio-economic conditions prescribed by the SSP scenarios and the assumptions that underpin the translation of qualitative SSP storylines into quantitative model input parameters. Uncertainties in the assumptions for population growth, technological change and cropland degradation were found to be the most important for global cropland, while uncertainty in food consumption had less influence on the results. The uncertainties arising from climate variability and the differences between climate change scenarios do not strongly affect the range of global cropland futures. Some overlap occurred across all of the conditional probabilistic futures, except for those based on SSP3. We conclude that completely different socio-economic and climate change futures, although sharing low to medium population development, can result in very similar cropland areas on the aggregated global scale.

1

Land use and land cover change (LULCC) is a fundamental aspect of global environmental change, but large uncertainties exist in estimating the effect of multiple drivers on LULCC in the future (Brown et al., 2014). A range of different models and scenarios have been used to project future cropland areas to 2100 with estimates in the range of 930 to 2670 Mha (Alexander et al., 2016; Prestele et al., 2016). This compares with today's cropland areas of around 1530 Mha. The large differences in these projections reflect uncertainties in process understanding, the use of different models to represent these processes and the direction of development of multiple drivers, including food demand and agricultural 
productivity (Schmitz et al., 2014; Smith et al., 2010). The direction of socio-economic drivers is referred to as deep uncertainties, which are addressed through the use of scenarios (van Vuuren et al., 2008). Cropland projections at the high end of the projected uncertainty range for global cropland would have profound consequences for, for example, global carbon and nitrogen fluxes, the global water balance, biodiversity, and other ecosystem services (Lindeskog et al., 2013; Pereira et al., 2012; Zaehle et al., 2007). Hence, quantifying and understanding the inherent uncertainties in the drivers of LULCC has important consequences for policy responses to support sustainable development. However, the effects of uncertainties in the underlying scenario assumptions have not been systematically quantified for global cropland projections.

Scenarios are characterized by storylines that describe assumptions about key drivers and processes from which model input parameters are interpreted (Rounsevell and Metzger, 2010). These parameter interpretations are by definition deterministic within a scenario context, since they do not consider the uncertainties associated with the interpretation process itself. By contrast, probabilistic approaches examine system uncertainties by assigning probability distributions to input variables (reflecting uncertainties about scenario assumptions) to assess the influence of uncertainty on system outputs (van Vuuren et al., 2008). The conditional probabilistic approach combines the strength of scenarios in addressing deep uncertainties with the probabilistic approach that explores the uncertainties in the assumptions about model input parameters (O'Neill, 2005; van Vuuren et al., 2008). In this case, the probability distribution of each model input parameter is conditional on the internal logic and assumptions within the contextualizing scenario. Hence, conditional probabilistic futures are useful in exploring parameter uncertainty within and across scenarios (Brown et al., 2014; van Vuuren et al., 2008).

In this paper, we present probabilistic futures of global cropland that are conditional on scenario assumptions. In doing so, we quantify the uncertainties within these assumptions, as well as representing the deep uncertainty across different scenarios. The assessment is based on the following key questions:

- How will cropland area evolve until 2100 in response to socio-economic drivers and climate change?

- Will future ranges of global cropland for different scenarios overlap due to differences in socio-economic conditions and/or due to uncertainties in model input parameters?

- How does the influence of the uncertainties in model input parameters change through time?

We use a scenario framework based on the five shared socio-economic pathways (SSPs) and develop a scenario ma- trix combining the five SSPs and four representative concentration pathways (RCPs). This scenario matrix is filled with probabilities based on the assumption that a given SSP will correspond to a given RCP. For each SSP, we derive RCP-specific input (yields in this case) applying the scenario matrix. The resulting conditional probabilistic futures are named F1-F5, where the numbers 1-5 correspond to SSP1-5. The RCP-SSP scenario framework was used since it is the most recent scenario approach for global environmental change research (Ebi et al., 2014; O'Neill et al., 2016; van Vuuren et al., 2011, 2014). We apply these scenarios to a global-scale, socio-economic model of agricultural land use change (the Parsimonious Land Use Model, PLUM; Engström et al., 2016) in combination with crop yield time series derived from the dynamic global vegetation model, LPJ-GUESS (Lund-Potsdam-Jena General Ecosystem Simulator; Lindeskog et al., 2013; Smith et al., 2001). PLUM has been benchmarked against different models and scenario studies in a land use model intercomparison exercise (Alexander et al., 2016; Prestele et al., 2016) that has demonstrated its consistency in comparison with other global cropland simulations. Because of its rapid runtimes, PLUM can explore uncertainties across its input parameter space (Engström et al., 2016) and hence is appropriate for use in probabilistic simulations requiring multiple model iterations.

\section{Materials and methods}

\subsection{Conditional probabilistic futures within the SSP-RCP scenario framework}

To construct the conditional probabilistic futures (F1-F5) we used qualitative and quantitative information from the SSPs directly and quantitative information from the RCPs indirectly as input to PLUM (Fig. 1).

The SSPs describe plausible, alternative societal development pathways over the 21 st century in the absence of climate change or climate policies (O'Neill et al., 2016, 2013). The SSP-specific development of society and sectors, such as energy and land use, results in varying challenges for mitigation and adaptation to climate change (O'Neill et al., 2016). In SSP1, economic growth and technological development are strong, sustainable solutions are preferred and population growth is low, resulting in small challenges for mitigation and adaptation. By contrast, SSP3 presents great challenges for mitigation and adaptation because it is characterized by high population growth but low economic and technological growth, combined with resource-intensive lifestyles. SSP2 describes a world with medium population growth and technological and economic development, resulting in medium challenges for mitigation and adaptation. The remaining two scenarios (SSP5 and SSP4) present contrasting challenges for mitigation and adaptation. SSP5 is a fossilfuel-based world that is focused on development (low population growth, high economic and technological growth) and 


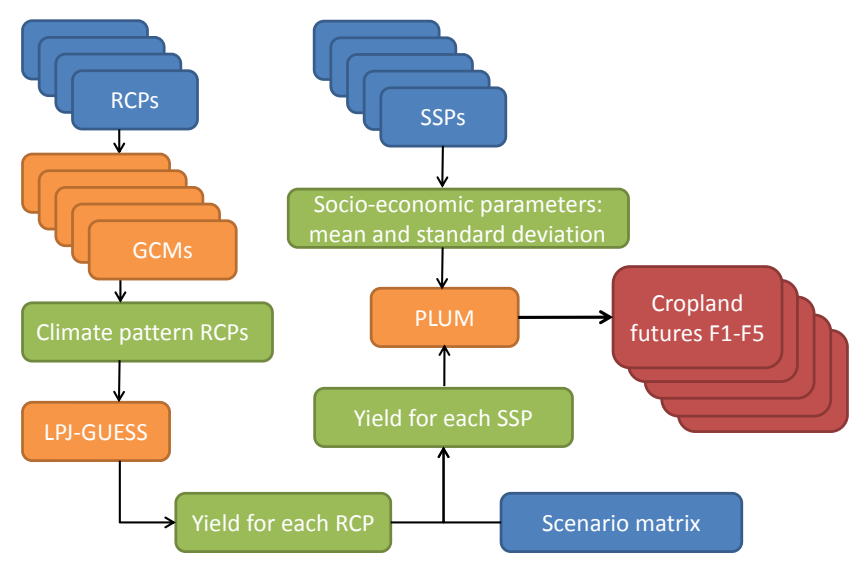

Figure 1. The SSP-RCP modelling framework. The RCPs and SSPs, as well as the scenario matrix (author judgement about the distribution of RCPs conditional on SSPs), are input to the model (indicated in blue). Models (indicated in orange; GCMs: general circulation models) use input or results of other models (intermediate results, indicated in green). The final outputs of the modelling framework are the cropland futures F1-F5 (indicated in red).

presents a great challenge for mitigation, but a small challenge for adaptation. SSP4 presents a small challenge for adaptation but a great challenge for mitigation because inequality is high across and within countries, and various levels of economic and technological development benefit the global elite.

In the modelling framework presented here, the different socio-economic pathways were combined with different levels of climate change associated with the four RCPs. The RCPs are defined by their forcing targets from 2.6 to $8.5 \mathrm{~W} \mathrm{~m}^{-2}$ at the end of the $21 \mathrm{st}$ century and trajectories of emission changes (van Vuuren et al., 2011). The radiative forcing of the RCPs is likely to correspond to global mean temperature increases between 0.3 and $4.8^{\circ} \mathrm{C}$ by the end of the 21st century (2081-2100) relative to the 1986-2005 global mean temperature (in the 5 to $95 \%$ range; Collins et al., 2013). The impact of climate change on crop yields was estimated for all RCPs by running LPJ-GUESS with climate inputs derived from five different general circulation models (GCMs; Collins et al., 2011; Dufresne et al., 2013; Dunne et al., 2013; Iversen et al., 2013; Watanabe et al., 2011).

The SSPs and RCPs were combined within a scenario matrix to reflect assumptions about the plausibility of an RCP arising from an SSP. Theoretically, all cells within this matrix are possible, but not all combinations of SSPs and RCPs are equally plausible and consistent (van Vuuren and Carter, 2014; van Vuuren et al., 2014). For instance, van Vuuren et al. (2012) indicate that emissions are only likely to be as high as assumed under RCP8.5 with large-scale use of fossil fuels, driven either by rapid economic growth (and little substitution towards less carbon-intensive fuels) or very high population growth. By contrast, for the matrix cells at the lower end of the RCP range ( 2.6 and $4.5 \mathrm{~W} \mathrm{~m}^{-2}$ ), the SSPs would need to assume strong mitigation efforts, but this would be less plausible for the SSPs with great challenges to mitigation. Here, we use the SSPs as reference scenarios as described in O'Neill et al. (2016) without introducing any specific mitigation policies (as could be done using the shared policy assumptions, SPAs; Kriegler et al., 2014). The SPAs define key attributes of climate policy, e.g. climate goals, policy regimes and measures (Kriegler et al., 2014). However, some SSPRCP combinations remain unlikely either at the low or high end. Without the introduction of specific mitigation policies, the SSP-RCP combinations are referred to as reference scenarios (O'Neill et al., 2016).

The conditional probabilistic approach was implemented through the following steps (van Vuuren et al., 2008):

1. identification of uncertain parameters;

2. estimation of the conditional probability ranges associated with these parameters, i.e. their probability density functions (PDFs);

3. use of Monte Carlo sampling across the PDFs to undertake multiple simulations;

4. identification of the uncertainty ranges in model outcomes and the determinants of model uncertainty.

Thus, the uncertainty ranges of the global model output variables arise from

a. uncertainties in the PLUM socio-economic input parameters and

b. uncertainties in climatic variation and sampling from the scenario matrix for the crop yield simulations.

The effect of a. was explored in combination with b. for global output variables. We hypothesize that the effect of $b$. is smaller than the effect of a. on the range of global cropland change. This hypothesis was tested by undertaking model runs in which only the socio-economic parameter uncertainties were explored. This stepwise approach is described in more detail below (Sect. 2.3: steps 1-3 for a.; Sect. 2.4: steps 1-3 for b; Sect. 2.5: step 4).

\subsection{PLUM simulations - descriptions of future cropland}

PLUM simulates agricultural land use in terms of cropland for $160^{1}$ countries (Engström et al., 2016). The model is based on a simple demand and supply strategy, where demand of agricultural products is driven by population, economic development and dietary changes. The supply of agricultural products, indicated by cereals, is met by a simple

\footnotetext{
${ }^{1}$ The availability of input data determines the number of countries included. In the evaluation version in Engström et al. (2016) 162 countries were included, whereas 160 are used here.
} 
trade mechanism, where all countries are assumed to have access to the global market. Changes in cropland are assumed to be proportional to changes in cereal land, applying a constant country-specific cropland-cereal-land ratio derived from FAOSTAT data in the baseline year of 2000 (for a detailed description of PLUM, see Engström et al., 2016). Globally, cereal land alone accounted for $60 \%$ of cropland in 2010 (FAOSTAT, 2015). PLUM can reproduce global historic agricultural land use change (1990-2010), and results have demonstrated that agricultural land use is highly sensitive to uncertainties in crop yield growth rates (Engström et al., 2016). To estimate the temporal trends and changes in spatial patterns of crop yields in response to climate change, country-level cereal yields were derived from the global dynamic vegetation model LPJ-GUESS (Lindeskog et al., 2013; Smith et al., 2001). LPJ-GUESS accounts for the effects of temperature, precipitation and atmospheric $\mathrm{CO}_{2}$ concentrations on crop yields and the productivity of natural vegetation. It models the yields of 11 globally important crops, including wheat, maize and rice (Lindeskog et al., 2013), and also accounts for management options such as sowing and harvesting in response to climatic conditions.

To derive LPJ-GUESS country-level projections of actual and potential cereal yield, LPJ-GUESS simulations were performed on a $0.5^{\circ}$ grid from 2000 until 2100 for four cereal crops (wheat, maize, millet/sorghum and rice), both rain fed and irrigated. To calculate the yearly actual yield per grid cell, the per grid cell share of irrigated vs. rain-fed area in the year 2000 was derived from the MIRCA (monthly irrigated and rainfed crop areas) data set (Portmann et al., 2010) and applied over the entire simulation period. For potential yields, we chose the maximum of either rain-fed or irrigated yields in each grid cell where the crop was present in the MIRCA data set. Naturally in most cases irrigated yields are larger and less fluctuating. The per grid cell actual and potential yields for the year 2000 were then scaled to the grid cell actual and potential yield from Mueller et al. (2012) in order to establish the difference (yield gap) between actual and potential yields. This scaling factor was then used for all years in the yield time series. The yield time series were then aggregated to the country level based on the area fractions from the MIRCA data set. These aggregated county level time series of actual and potential yield were used to sample yield time series as input to PLUM (Sect. 2.4.3). In PLUM, the yield gap was modelled to change over time depending on three scenario parameters describing technological change (Fig. 2). These three parameters describe the strength of technological change per se and the investment and distribution of yield-improving management practices (see Appendix A). The potential yield is not influenced by the technological change parameters. Thus, further increases in potential yields arising from crop breeding and improved agricultural management practices are not included here (see Fischer et al., 2014, for a review).

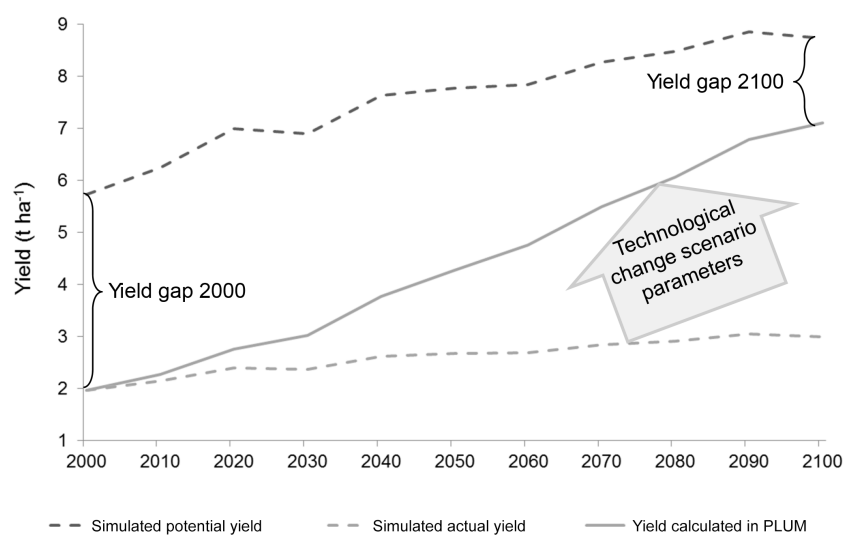

Figure 2. Decreasing yield gap for Ukraine. The scenario parameters related to technological change determine how rapidly the yield gap decreases over time (the arrow only being symbolic, indicating the drivers of changing yield gap).

The country-level actual yields calculated in the previous step might differ slightly from the country statistics from FAOSTAT on which PLUM is based. Thus, as a final step, the yield calculated in PLUM was scaled to match yields reported in the year 2000 (FAOSTAT, 2015). The scaling factor for the year 2000 was applied throughout the simulation period. An example of the yield calculations is given in Fig. 2, for Ukraine. This example uses the socio-economic assumptions from SSP5 and the yield projections driven by RCP6.0. Carbon fertilization has a strong effect on crop yields; e.g. for Ukraine potential yields are simulated to increase from below 6 to above $8 \mathrm{tha}^{-1}$ from 2000 to 2100 (dark grey dashed line, Fig. 2). Actual yield is simulated to increase by roughly $1 \mathrm{tha}^{-1}$ by the end of the 21 st century (light grey dashed line, Fig. 2). However, the strong economic and technological change in SSP5 results in a tripling of yields during the period 2000-2100 (grey line, Fig. 2) and thus a decrease in the yield gap for Ukraine.

\subsection{Uncertainties related to the socio-economic input parameters of PLUM}

\subsubsection{Identifying uncertain parameters in PLUM}

The computational costs of PLUM are relatively low since it is a simple model that operates on the country scale, with global parameterization and a focus on aggregated global outputs. This allows a wide range of socio-economic input parameters to be tested. Thus, in addition to input parameters that affect cropland changes directly, we also analysed input parameters that affect other global output variables such as meat consumption and cereal demand. 


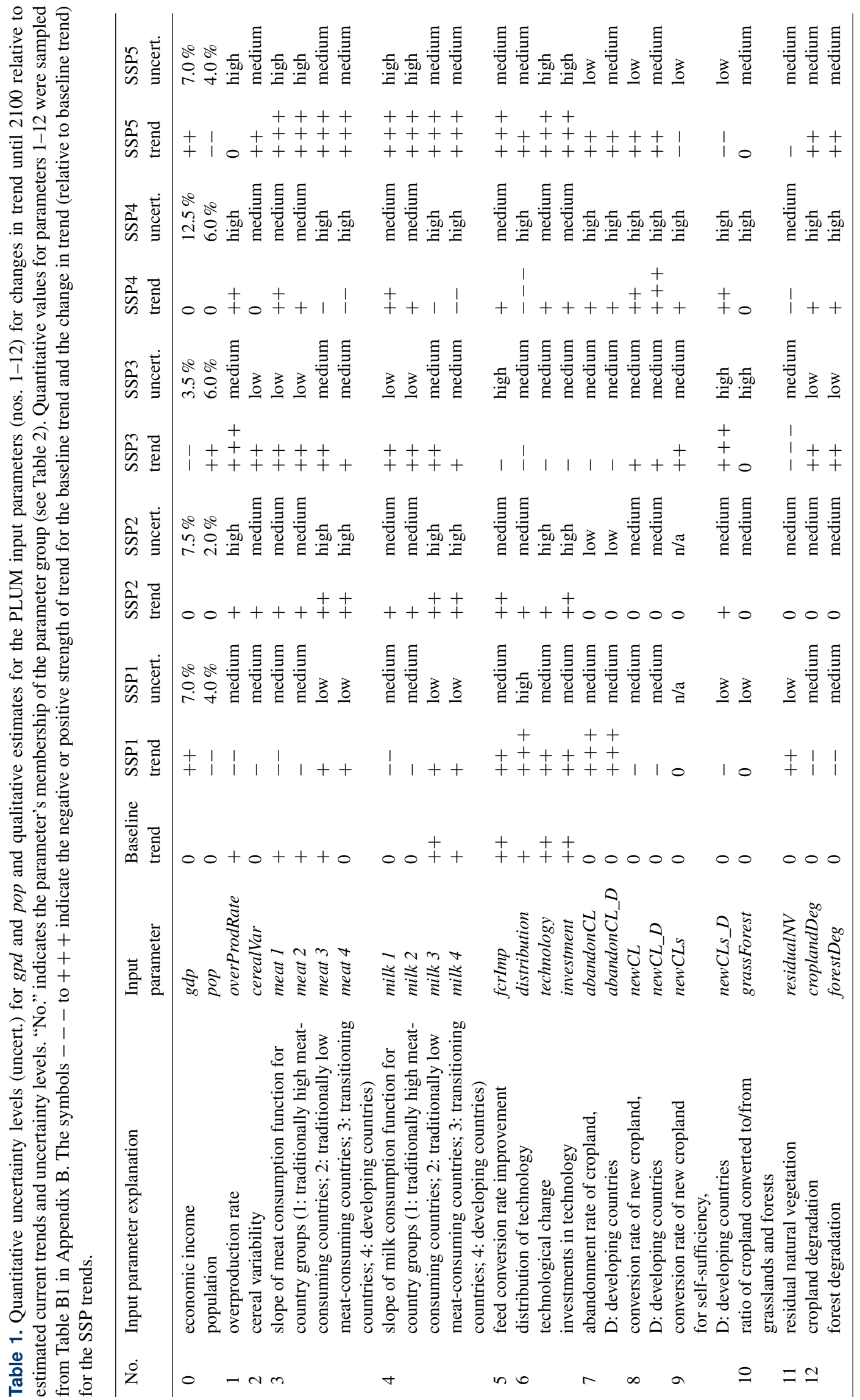


Table 2. PLUM input parameter groups and the influence of SSP scenario elements (from O'Neill et al., 2016). In PLUM several of the input parameters were grouped together conceptually, as indicated by the parameter group number (no.). For example, there are four input parameters that describe meat consumption trajectories of different income and cultural groups (meat1-meat4, see Table 1), which all belong to meat consumption, parameter group no. 3 .

\begin{tabular}{|c|c|c|}
\hline No. & PLUM input parameter groups & Influencing scenario elements (O’Neill et al., 2016) \\
\hline 1 & Level of food production & $\begin{array}{l}\text { International trade, globalization, international cooperation, } \\
\text { environmental policy, policy orientation, institutions, agriculture }\end{array}$ \\
\hline 2 & Cereal consumption & Consumption and diet \\
\hline 3 & Meat consumption & Inequality, consumption and diet \\
\hline 4 & Milk consumption & Inequality, consumption and diet \\
\hline 5 & Efficiency of animal production & Technology development, agriculture \\
\hline 6 & Technological change for yield & Technology development and transfer, agriculture \\
\hline 7 & Cropland reduction & Land use \\
\hline 8 & Cropland expansion & Institutions, land use \\
\hline 9 & Cropland for self-sufficiency & International trade, globalization, land use \\
\hline 10 & Grassland vs. forest & Environmental policy \\
\hline 11 & Remaining natural vegetation & Environmental policy, policy orientation \\
\hline 12 & Land degradation & Environmental policy \\
\hline
\end{tabular}

\subsubsection{Assessment of the conditional probability ranges informed by the SSPS}

The conditional probability ranges describe the uncertainty ( \pm 1 standard deviation) around the mean of each input parameter. The following describes the assessment of the conditional probability ranges both for input parameters parameterized with country-level time series (no. 0; see Table 1: economic development indicated by gross domestic product $g d p$ and population $p o p)^{2}$ and global socio-economic input parameters (nos. 1-12; see Tables 1 and 2).

For each SSP, the mean of the parameters $g d p$ and pop was specified using the country-level projections from the SSP Database (SSP Database, 2015). We used the population projections "IIASA-WiC v9_130115" from 2010 to 2100 (KC and Lutz, 2016; SSP Database, 2015) and combined these with population data from the World Bank for the years 2000-2009 (World Bank, 2015). For the economic development projections, the "OECD Env-Growth v9_130325" projections from 2000 to 2100 were selected (SSP Database, 2015) that have the advantage of providing the countryspecific PPP (purchasing power parity)-MER (market exchange rate) conversion rates required by PLUM.

The applied population and GDP projections are SSP and country specific but retain uncertainty with respect to the interpretation of the underlying drivers, model structures and country groupings. These uncertainties were explored with the uncertainty levels of the global parameters $g d p$ and $p o p$ (Table 1). The uncertainty levels of $g d p$ were orientated on the coefficients of variation calculated from three different projections for global GDP available in the SSP database (SSP Database, 2015) and set to be 7, 7.5, 3.5, 12.5 and $7 \%$ for SSP1, 2, 3, 4 and 5 respectively. For population

${ }^{2}$ Throughout the paper, parameter names are given in italics. projections, differences in input assumptions and models resulted in coefficients of variation between 2 and $21 \%$ in 2100 (SSP Database, 2013, 2015; O'Neill, 2005). Population projections are very sensitive to fertility rates (Lutz and KC, 2010), so qualitative uncertainty levels (low, medium, high) were estimated based on the heterogeneity of assumptions for different fertility groupings (high-fertility countries, lowfertility countries and rich OECD countries; KC and Lutz, 2016; O'Neill et al., 2016). The low, medium and high uncertainty levels were set to be $\pm 2, \pm 4$ and $\pm 6 \%$ of total population size in 2100 respectively; see Table 1.

For the mean values of the other global model input parameters, we started with the historic mean value of each parameter (Engström et al., 2016) and assessed a baseline trend qualitatively (Table 1). The positive or negative strength of the qualitative baseline trends were characterized with symbols $(---,--,-, 0,+,++,+++)$. Similarly, the changes in trends were estimated for each SSP based on an interpretation of the SSP storylines. For transparency, we provide a summary of our interpretation of the SSPs based on the existing SSP narratives (O'Neill et al., 2016) (see Appendix B). We also recorded the scenario elements of the existing SSP narratives (O'Neill et al., 2016) that were assumed to influence changes in the PLUM input parameters (Table 2).

Low, medium or high uncertainty levels were attributed to each input parameter and scenario. These uncertainty levels comprise several sources of uncertainty: the understanding of the world characterized by a storyline, the knowledge about the global average development of a driver, and the heterogeneity and variability of the model parameter across and/or within countries. The change in trend and uncertainty level (see Table 1) was interpreted for each model input parameter conditional on each SSP using the scenario elements in Ta- 
ble 2. For example, we assumed that the scenario elements of "technology development and transfer" and "agriculture" (Table 2) influence the input parameters of yield development (for both cereals and animal products: fcrImp, technology and investment in Table 1).

For SSP5, technology development and transfer are described as being rapid and agriculture is highly managed and resource-intensive with a rapid increase in productivity (O'Neill et al., 2016). We interpreted this as strong improvements in feed conversion ratios (5: fcrImp, +++ ; Table 1) and a strong trend in investments and technology for yields (6: technology, +++ ; investment,+++ ; Table 1 ).

Some PLUM input parameters are not global but based on country groups to reflect variability in local contexts, such as meat consumption (Table 1, no. 3: meat 1-4). For example, in SSP1, the scenario element "consumption and diet" is described as "low growth in material consumption, low-meat diets, first in HICs (High Income Countries)" (O'Neill et al., 2016), resulting in differentiated estimates for countries parameterised by meat 1 (traditionally high meat consumption) compared to countries belonging to meat 3 and meat 4 (transitioning and low-income countries (see Engström et al., 2016, for details on consumption classes). More detailed examples of the logic in assigning changes in trends and uncertainty levels to input parameters conditional on each SSP are provided in Appendix B.

These qualitative estimates of changes in trend and uncertainty levels for the PLUM input parameters in Table 1 were translated into quantitative values (mean and standard deviation characterizing the PDF; see Sect. 2.3.3) by sampling from an input parameter value matrix (input parameters in rows, symbols --- to +++ in columns; see Appendix B, Table B1).

\subsubsection{Monte Carlo sampling of socio-economic parameters}

To assess the uncertainty in projected model output, Monte Carlo sampling was used to create different sets of PLUM input parameters from PDFs conditional on each SSP. We assumed a normal distribution for most PLUM input parameters since it seems unlikely that extreme values would occur frequently. Moreover, extreme values would be applied to all countries simultaneously due to the nature of the global parameterization (i.e. in one model run all countries have the same value). The choice of normal distributions was also supported by the normal distribution seen in the inter-country variability in historic data for global parameters of, e.g., meat and milk consumption. The land conversion parameters (nos. 7-9, Table 1) are an exception, as their values only limit the internally calculated land conversion rates. Each maximum value was thought to be equally plausible and so we assumed the land conversion rates to be uniformly distributed. The PDFs were constructed by using the mean and standard deviation (minimum and maximum for land conversion parameters) derived for each SSP (Table B1, Appendix B). All PDFs were truncated by -3 standard deviations at the lower end and +3 standard deviations at the higher end of the distributions. In some cases, the PDFs were truncated by 1 standard deviation, e.g. for the lower bound of population in SSP1, as it was assumed unlikely that population would decrease much more than projected for this scenario (see Appendix B). For each iteration, a random number was drawn to calculate an input parameter from the appropriate PDF. All countries were assumed to draw the same value from the same distribution of parameter values for each run. This simplified approach could lead, arguably, to an overestimation of uncertainties, since in reality between-country differences in deviations from the mean would be expected. In the uncertainty analysis we did not investigate the possible effects of correlation between input parameters because the use of scenarios ensures the consistency across parameter mean values. For example, in SSP1, the relatively high mean values for all three input parameters that influence yield development (distribution, technology, investment; see Table 1) are all consistent with the storyline of relatively strong technological growth and technology transfer. Two sets of Monte Carlo simulations were performed. For the first set only the socio-economic parameters were sampled and the mean yield of each SSP (derived from the RCP-SSP matrix; see Sect. 2.4.3) was used (3600 runs per SSP). For the second set, in addition to the socio-economic parameters, crop yields were also sampled based on the combined uncertainty from the RCP-SSP matrix and GCM variability; see Sect. 2.4.3. Because of the increased sampling in these simulations, the number of iterations was increased to 7200 per SSP.

\subsection{Uncertainties arising from climate change and climate variability}

\subsubsection{Identifying parameters informed by the RCPs}

The RCPs cover a wide range of emission and concentration scenarios: at the low end with the mitigation pathway RCP2.6 and at the upper end with the high-emission pathway RCP8.5 (van Vuuren et al., 2011). For a given RCP, modelled global average temperatures between different GCMs can vary by up to $1^{\circ} \mathrm{C}$ in 2100 . The global totals and spatial patterns of other climatic variables, e.g. precipitation, also vary strongly between GCMs (Amiro et al., 1999; Knutti and Sedlacek, 2013). The effect on the global terrestrial carbon balance of between-GCM variability can be larger than the difference between concentration pathways (Ahlström et al., 2013). Thus, a potentially important source of uncertainty in the crop yield projections is the climate variability projected by the different GCMs.

A second source of uncertainty in future crop yield projections is that each SSP could, though with different probabilities, lead to different RCPs. To address this uncertainty, the 
Table 3. Conditional probabilities (ranging from very low to very high) of SSPs resulting in RCPs based on authors' judgement.

\begin{tabular}{lllll}
\hline & RCP 2.6 & RCP 4.5 & RCP 6 & RCP 8.5 \\
\hline SSP1 & very low & medium & medium & 0 \\
SSP2 & 0 & very low & high & low \\
SSP3 & 0 & low & high & medium \\
SSP4 & 0 & medium & high & very low \\
SSP5 & 0 & very low & medium & high \\
\hline
\end{tabular}

likelihood of SSP-RCP combinations was estimated (in the absence of mitigation strategies) as described below.

\subsubsection{Assessment of the SSP-RCP scenario matrix}

The SSP-RCP probability judgements were combined with the interpretation of the SSP storylines (O'Neill et al., 2016) to estimate the conditional probabilities (van Vuuren and Carter, 2014) given in Table 3. The sustainability assumptions in the SSP1 scenario with respect to environmental and energy policies could curb emissions sufficiently to achieve RCP2.6, but it is more plausible for the SSP1 scenario to arrive at greenhouse gas concentrations consistent with RCP4.5 and RCP6.0 (medium probability).

Many medium reference scenarios result in forcing levels around $6-7 \mathrm{~W} \mathrm{~m}^{-2}$ based on a continued reliance on fossil fuels and medium population and economic growth (Clarke et al., 2014). We interpreted this as a high likelihood of forcing levels similar to RCP6.0 being achieved by SSP2, SSP3 and SSP4. High-energy intensity in low-income countries and material-intensive consumption make RCP8.5 plausible in an SSP2 world, although this is assumed to have a low probability of occurrence. Given the relatively low economic growth in SSP3, we assume that forcing levels would lead to RCP6.0 or RCP8.5, with a lower probability for RCP8.5 (Table 3).

The very high-emissions pathway of RCP 8.5 can only be achieved with a combination of, for example, high economic growth and reliance on fossil fuels. The divergent development in SSP4 for the few elite and the many fewer privileged people is difficult to estimate. We assumed that SSP4 has a high probability of resulting in forcing around RCP6.0 or possibly lower. The latter is based on the moderate population growth and the original positioning of the scenario (small mitigation challenge). The majority of the population in SSP4 cannot afford a material-intensive lifestyle, making RCP8.5 forcing unlikely. For SSP5 we assumed that the material-intensive lifestyle combined with very high economic growth would lead to RCP8.5 with a high probability (comparable to the assumptions for the SRES (Special Report on Emissions Scenarios) A1F1 scenario; see van Vuuren and Carter, 2014).

The qualitative probabilities in Table 3 were translated into quantitative values in Table 4. We assumed that the qualita-
Table 4. Scenario matrix translated to quantitative probabilities.

\begin{tabular}{rrrrrr}
\hline & RCP 2.6 & RCP 4.5 & RCP 6 & RCP 8.5 & Sum \\
\hline SSP1 & 0.0909 & 0.4545 & 0.4545 & 0.0000 & 1 \\
SSP2 & 0.0000 & 0.0909 & 0.6818 & 0.2273 & 1 \\
SSP3 & 0.0000 & 0.1667 & 0.5000 & 0.3333 & 1 \\
SSP4 & 0.0000 & 0.3704 & 0.5556 & 0.0741 & 1 \\
SSP5 & 0.0000 & 0.0741 & 0.3704 & 0.5556 & 1 \\
\hline
\end{tabular}

tive notions of very high, high, medium, low, and very low probability translated into quantitative probabilities of 0.9 , $0.75,0.5,0.25$ and 0.1 respectively. The assigned probabilities were normalized so that the sum of probabilities for each SSP equalled 1 (see Table 4).

\subsubsection{Sampling the climate-driven parameters: yields}

The probabilities of SSPs resulting in RCPs (Table 4) were combined with the uncertainties arising from the climate variability of the different GCMs. To do so, the aggregated country-level yield time series (described in Sect. 2.2) were calculated for each RCP-GCM combination. Yield time series calculated for different countries vary, depending on the underlying GCM. To account for this spatial variability, the deviations from the yields averaged per RCP $(\hat{Y})$ were decomposed using singular value decomposition (SVD, Eq. 1), where $Y$ is the yield projections for each GCM-RCP combination, $\hat{Y}$ is the mean over the GCM projections for each $\mathrm{RCP}$, and $U, S$ and $V$ are factors that can be used to reconstruct $Y-\hat{Y}$.

$U, S, V=S V D(Y-\hat{Y})$

This allows sampling of per country yield projections while preserving the patterns in spatial variability resulting from the GCM-RCP yield projections. From this we constructed four sets (one for each RCP) of 51 future yield projections, where 50 are random samples calculated using (Eq. 2) where $V$ is replaced with $\varepsilon \in N(0,1)$ and one set with the mean yield across the GCMs $(\varepsilon=0)$. 51 samples were chosen to allow enough variability in the effect of the GCMs on the yield projections.

$Y=\hat{Y}+U S \varepsilon, \quad \varepsilon \in N(0,1)$

Drawing on these four sets, the SSP-RCP matrix was used to weigh how much of the information from the different RCPs should be taken into account for each SSP. The resulting yield time series $\left(y_{i}\right)$ were sampled using a uniform distribution $\left(y_{i}, i \in U(0,50)\right)$, and the sample was used as input to PLUM together with the socio-economic parameters (see Sect. 2.3.3). 


\subsection{Analysis of uncertainty results and sensitivity assessment}

Cropland distributions with and without climate variability were analysed for the 7200 and 3600 runs respectively to the year 2100 with respect to convergence and or divergence across the five scenarios. We report the mean development and ranges at $95 \%$ confidence levels (corresponding to 2 standard deviations) for the global-scale, model outputs, i.e. population, GDP, cereal consumption, meat consumption, feed demand, cereal demand, cereal production, cereal yield and cropland. The word "likely", based on the IPCC's recommendation for uncertainty communication (Mastrandrea et al., 2010), was used to report results that are probable at 68-100\%. A global sensitivity analysis (GSA; Saltelli et al., 2008) was carried out to quantify the contribution of the input parameters to the uncertainty of the global cropland extent for all socio-economic model input parameters. The GSA was implemented as previously described in Engström et al. (2016), with $n=5000$ and $p=24$, requiring 130000 runs for each scenario (according to $(p+2) \times n=$ number of runs; Lilburne and Tarantola, 2009). We used the Sobol-Jansen method (Pujol et al., 2015), which is an R implementation of the Monte Carlo estimation of Sobol sensitivity indices (Jansen, 1999; Saltelli et al., 2010), as a method that is robust for large and small total indices (Saltelli et al., 2010). The total indices (hereafter, total importance) consist of the first-order effect of each input parameter and their interaction effects. We excluded the parameters that describe the allocation of cropland changes to forested or grassland areas (grassForest) and the forest degradation rate (forestDeg) for the global sensitivity analysis because they have no direct impact on global cropland. We used the GSA to visualize the total importance, which describes the main effect and interaction effects of the uncertainty for each input parameter on the model output (cropland).

\section{Results}

\subsection{Ranges of global cropland projections}

Global cropland area increases initially for all scenarios but declines in the simulations for F1 after 2015 (Fig. 3a). F1 continues to decline to $963 \pm 140$ Mha of global cropland by 2100. All other cropland futures increase until 2030; thereafter, the rate of increase slows for F2, F4 and F5. Mean global cropland peaks for F5 in 2045, and shortly afterwards for F2, and then decreases to $1400 \pm 382$ Mha in 2100 for F5 and $1590 \pm 332$ in 2100 for F2. For F3, global cropland continues to increase over the entire simulation period, reaching $2280 \pm 200$ Mha in 2100. Mean global cropland changes for F4 are very moderate throughout the simulation period and are within the cropland development of the other scenarios (1540 Mha in 2100). However, the range of cropland futures for $\mathrm{F} 4$ for the $95 \%$ confidence interval in 2100 is very wide

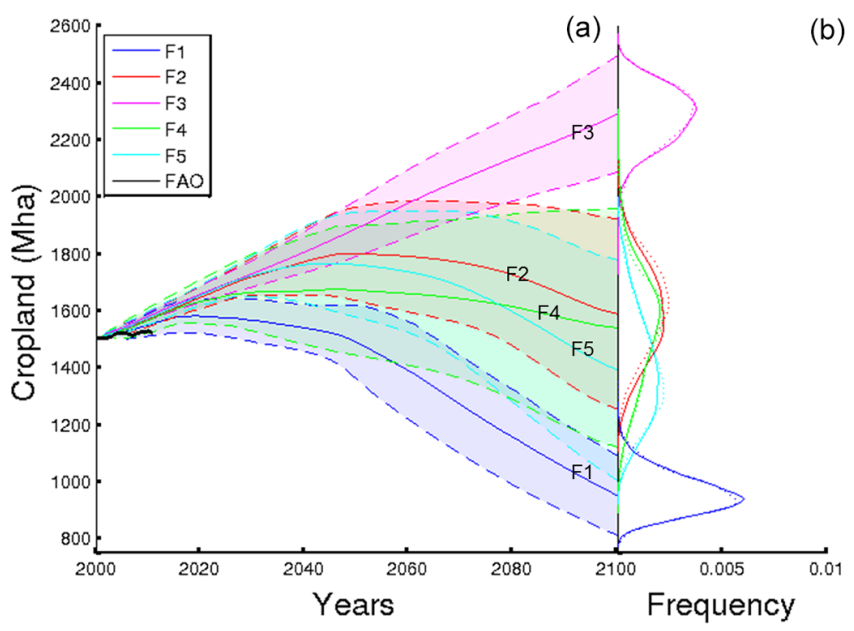

Figure 3. (a) Cropland development from 2000 to 2100 for the five cropland futures (solid line: mean; range with dashed lines: \pm 2 standard deviations). (b) PDFs fitted to all runs for each scenario in 2100 , solid lines are runs with sampling yield variations due to GCM patterns and the scenario matrix, and dashed lines are runs where the mean yield was used.

(1126-1954 Mha). The cropland distribution of F4 overlaps with the cropland distributions of all other scenarios, as do the cropland distributions of F2 and F5. F1 by contrast has the smallest cropland range, which is also indicated by its peaked distribution (Fig. 3b).

The cropland distribution for F1 is skewed toward the higher end, which is due to the truncated distribution of uncertainties in the population projections. For the same reason, the distribution of F3 is slightly skewed toward the lower end. The cropland distribution in F3 is also peaked, indicating that the confidence in the model outcomes for F1 and F3 are the highest, despite the fact that these two scenarios show divergent global cropland development.

The variability in yields arising from the five GCMs and sampling from the SSP-RCP matrix does little to change the shape of the global cropland PDFs (Fig. 3b, comparing solid lines (with yield variation) to dashed lines (mean yield)). For cropland futures with flat distributions (F2, F4 and F5), the distributions with climate variability (solid lines) are slightly less peaky than without climate variability (dashed lines). This indicates that the climate variability contributes more to the overall uncertainty of global cropland areas for scenarios with larger overlap of global cropland outcomes (F2, F4 and F5), compared to the cropland futures F1 and F3. Overall, the effect of climate change variability and sampling from the SSP-RCP matrix is very small. However, the inter-annual variability of yields due to variations in climate patterns is considerable (not displayed here). 

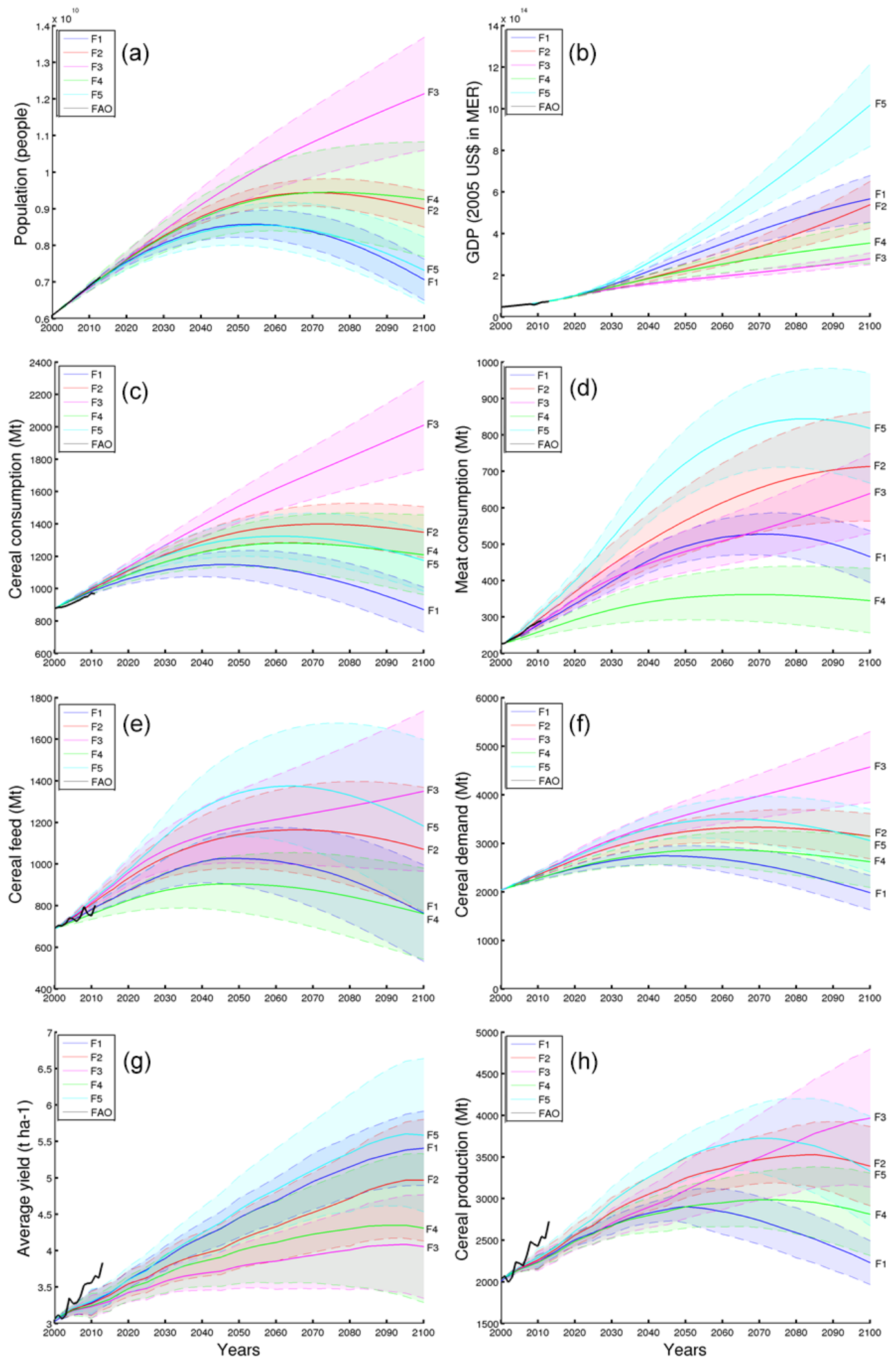

Figure 4. Global population, GDP, cereal consumption, meat consumption, cereal feed, cereal demand, mean cereal yield and cereal production for the five scenarios F1-F5. Solid lines indicate the scenario mean; dashed lines indicate the range based on the mean \pm 2 standard deviations. 


\subsection{Socio-economic dynamics influencing cropland futures}

The strongly overlapping cropland ranges for the F2, F4 and also F5 scenarios are caused by the assumed uncertainties in the trends of the different input parameters but also by the counteracting effect of different scenario drivers leading to similar cropland futures. Conversely, the distinct development of cropland for the F1 and F3 scenarios is mainly due to the reinforcing dynamics of drivers as described below.

In contrast to the other population scenarios, the total population size in F3 does not peak in the 21st century but grows continuously to $12.1 \pm 1.5$ billion people by 2100 (at the $95 \%$ confidence interval, Fig. 4a). This steady increase in population influences cereal consumption, cereal demand and (less clearly) cereal production (Fig. 4c, f and h) and thus cropland (Fig. 3). The strong population growth and therefore high food demand is counteracted by the low economic growth in F3, which results in the relatively lower consumption of animal products (Fig. 4d), corresponding to $53 \mathrm{~kg}$ of meat per person in 2100. However, in spite of this, slow technological change reinforces the high demand for cereals due to the steady increase in cereal feed (Fig. 4e).

For F5, despite a decline in total population size to $7.4 \pm 0.9$ billion people by 2100 , the consumption of animal products by 2100 is $820 \pm 150 \mathrm{Mt}$ meat and $1230 \pm 242 \mathrm{Mt}$ milk. The former corresponds to an average meat consumption of $110 \mathrm{~kg}$ meat per person in 2100 , which is comparable to current meat consumption rates of several developed countries, e.g. the US, Australia and Austria (FAOSTAT, 2015). The consumption of animal products is driven by economic growth and a very resource-intensive lifestyle for all consumption groups. For scenarios with strong technological growth, i.e. F1 and F5, the efficiency of the production of meat and dairy products increases and thus the demand for total cereal feed decreases.

Likewise, strong economic growth and technological change result in high global average cereal yields in 2100 for $\mathrm{F} 1$ and F5, $5.4 \pm 0.5$ and $5.6 \pm 1.0 \mathrm{tha}^{-1}$, respectively (Fig. 4g). For F5, the strong technological growth and resulting high yields and the high consumption levels balance the need for global cropland changes. For F1, the high yields and low consumption levels reinforce the diminishing need for cropland. By contrast, for F3, the increase in yield from 3.1 to $4.1 \pm 0.7 \mathrm{tha}^{-1}$ and the expansion of cropland from 1503 to $2280 \pm 200$ Mha in the period $2000-2100$ is not sufficient to keep up with rising cereal demand (including the demand from overproduction). In 2100 global cereal demand for F3 is $4550 \pm 718 \mathrm{Mt}$, but production is $3960 \pm 814 \mathrm{Mt}$. This inadequate global production would lead to cereal shortages and in a few cases to countries approaching their maximum available arable land. More importantly, the underproduction is due to incentives for exporting countries to increase their production, as well as cropland degradation, that are insufficient, though conceptually consistent with SSP3.

\subsection{Uncertainty in socio-economic model inputs}

The uncertainty in input parameters contributes differently to the uncertainty of global cropland futures over time (Fig. 5). For F1, population projections and technological change dominate uncertainty, the latter being especially important during the first quarter of the simulation period. Similarly, for F2, uncertainties in technological change and consumption are at first important, but after 2025 cropland degradation contributes largely to the uncertainty of global cropland. By contrast, population projections and technological change are the major contributors to the uncertainty range of global cropland for F3. For F4, uncertainties in the extent of land degradation, but also population projections and consumption and technological change, contribute to uncertainties in global cropland. Consumption and technological change become less important over the 21st century, compared with land degradation and population. These trends are similar for F5.

\section{Discussion}

For F2, F4 and F5, the uncertainty distributions of global cropland overlap greatly, with cropland changes over the $21 \mathrm{st}$ century within the range of -20 to $+17 \%$. This large overlap can be explained by counteracting drivers but also by larger uncertainties in the assumptions of model input parameters for the SSPs with contrasting directions of change in challenges for mitigation and adaptation (i.e. SSP4 and SSP5). By contrast, the F1 and F3 cropland futures are very distinct from one another, with a higher level of confidence, indicated by their peaked distributions. The simulated discrepancy between total demand and production in F3 indicates that a focus on regional production with limited trade can risk food insecurity for countries with limited potential for domestic production, which agrees with Brown et al. (2014). When considering F1 and F3, the F2, F4 and F5 range of cropland changes by 2100 ( -20 to $+17 \%)$ increases to a total range of -41 to $58 \%$ by 2100 compared with 2000 . These results lead to a slightly larger uncertainty range compared with deterministic scenario projections. For example, the cropland changes simulated by four different integrated assessment models (IAMs) were 1130-2100 Mha cropland by 2100 (RCP4.5-GCAM and RCP2.6-IMAGE; Hurtt et al., 2011). This corresponds to cropland changes from 1990 to 2100 of -25 to $+39 \%$ (Hurtt et al., 2011). It is difficult to compare these results directly since the IAM scenarios also include land-based mitigation options. For example, the cropland changes in RCP2.6-IMAGE were the result of a stringent mitigation scenario, where the production of biomass for bioenergy increased cropland areas (Hurtt et al., 2011).

No climate change mitigation actions were assumed in this study, although for SSP1 this would be plausible and consistent with the storyline. The simulated decrease in cropland for F1 suggests that land-based mitigation options, such as 


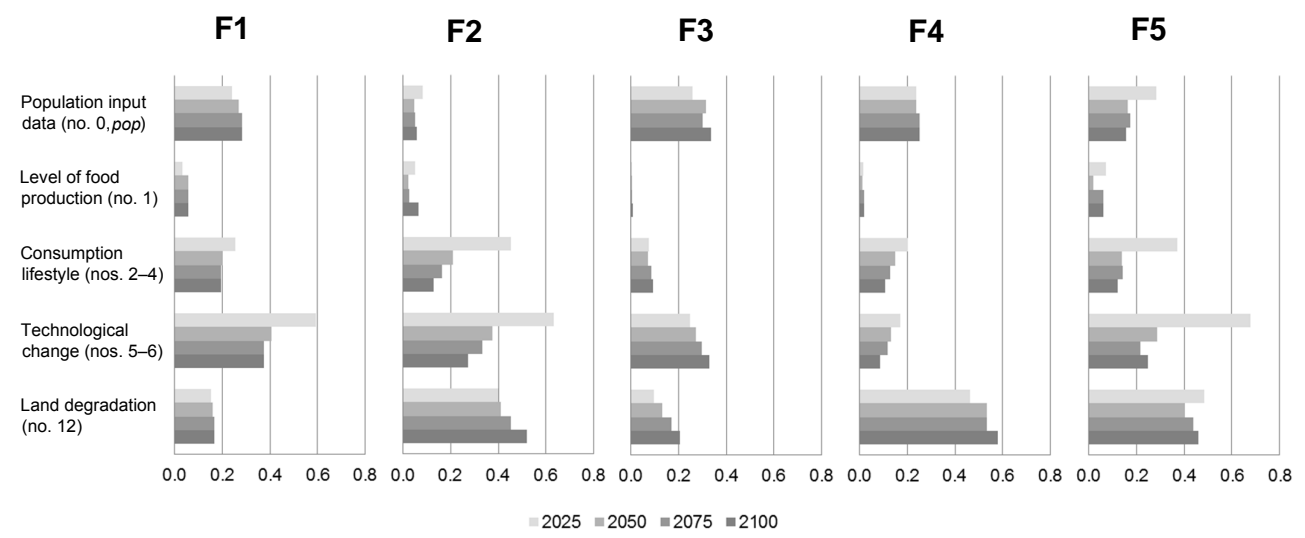

Figure 5. Total importance of global cropland for the futures F1-F5 to uncertainty of input parameters, aggregated to input parameter groups as in Table 2 (for non-aggregated results, see Fig. C1 in Appendix C).

bioenergy production, could be implemented on abandoned cropland without compromising food security or the provision of other ecosystem services. However, the global sensitivity analysis showed that for F1 to consistently achieve strong decreases in cropland areas, it is important to stay within the range of input assumptions. Among others, consumption patterns have to reflect the more resource efficient and environmentally friendly lifestyle that underlies this scenario. Achieving technological change and thus yield increase is important, as is decreased environmental degradation and thus decreased cropland degradation rates.

The LPJ-GUESS yield projections are at the higher end of the range of yield projections compared with other models (Rosenzweig et al., 2013) and likely overestimate the effect of $\mathrm{CO}_{2}$ fertilization since nitrogen limitations were not included in earlier versions of the model. However, these effects were counteracted in PLUM by (a) dividing global production by global cropland area to derive global average yield, which does not account for double cropping, and (b) assumptions about cropland degradation that are implemented as a production loss, which decreases the simulated global average yield. Future research will consider the management options in LPJ-GUESS coupled to PLUM (e.g. the use of irrigation and fertilization scenarios) and will improve the potential impacts of climate change on yields arising from pests and heat stress. Currently, heat stress implementation in LPJ-GUESS is limited to a shortened growing season, increased respiration and lowered photosynthesis.

The sensitivity analysis showed that assumptions about cropland degradation were important for cropland development across all scenarios. Cropland degradation was assumed to lead to an average global production loss of between $6 \%$ (F1) and $14 \%$ (F5) in 2100. This compares with an estimated global average of $20-40 \%$ loss of potential production on degraded agricultural areas only (Zika and Erb, 2009). Hence, the PLUM results of total global production (not only on degraded agricultural areas) appear to be of the right magnitude and the sensitivity analysis highlighted the importance of accounting for these uncertainties.

Global cropland was less sensitive to the uncertainties associated with the consumption input parameters, which, for example, describe the rate of increase or decrease in meat consumption for the four consumption country groups. PLUM represents cultural differences in consumption patterns between countries (based on four consumption groups), but this could potentially mask part of the total importance of the consumption input parameters because the correlation between the parameters of the four consumption groups was not considered. Additionally, cropland changes are likely to be underestimated in F5 because meat consumption increases strongly in countries currently defined as developing and global average meat consumption approaches $110 \mathrm{~kg}$ per person in 2100 . This would probably be associated with the intensification of animal production, which currently is not included in PLUM. Since intensive meat production would lead to an increase in the feed share derived from cereals, cropland areas would increase.

The use of a global model with reduced complexity risks missing potentially important dynamics and feedbacks, which could affect the magnitude of change (e.g. intensification in the livestock sector, as highlighted above). A reduced complexity model could also widen or limit the uncertainty range in outputs (depending on the balance between introduced uncertainty and better overall model performance). A further limitation of this approach are the judgements of the uncertainties in global model input parameters and their assumed distributions. Assessing these uncertainties is challenging because of the high degree of variability in development across 160 countries, in particular for SSP4 with large inequalities within and across nations. Furthermore, the use of normal distributions in the sampling of the input parameters might result in an underrepresentation of extreme outcomes. Thus, in the absence of better knowledge a relatively conservative approach was adopted here based on 
transparency in the assumed parameter ranges and distributions. Overall, the conditional probabilistic approach applied in PLUM led to cropland area ranges that are consistent with those reported by other scenarios and model intercomparison studies (Alexander et al., 2016; Hurtt et al., 2011; Prestele et al., 2016; Schmitz et al., 2014), which provides confidence in the modelling framework. PLUM is based on cereal demand and assumes that changes in cereal land are a reliable proxy for food demand and cropland changes with free-trade contributing greatly to meeting demands. For example, a change in the demand of cereals compared to other crops driven by climate change (either directly, or by enhanced demand for bioenergy) will require a revision to the constant cerealcropland ratio. Future model development will take bioenergy production into consideration. The global-scale projections with PLUM need to be interpreted under the assumption that the future agricultural system will not be fundamentally different from how we understand it today; an assumption that occurs in most global models. Clearly, in some scenarios the free-trade simplification might not be valid (e.g. in SSP3), a limitation that is balanced by PLUM having simple and transparent relationships. We argue that the possibility to perform rapid model runs outweigh drawbacks in the current model version that arise from less than perfect regional model performance.

High-end climate change impacts on yields (i.e. from solely applying RCP8.5) were not tested here, as the goal of this study was to create plausible and consistent cropland futures that address the uncertainties within each scenario rather than assessing the impact of each emission pathway. Excluding high-end climate change impacts on yields explains why the variability in climate change was found to have a relatively small impact on global cropland areas. Small differences in the climate change impacts on agricultural areas between RCP4.5 and RCP6.0 were found elsewhere (Wiebe et al., 2015), as well as the comparatively larger effects of RCP8.5. The approach used here, based on a matrix populated with probabilities, streamlined the total number of scenarios and simultaneously removed the need to compromise with single selections of SSP-RCP combinations.

\section{Conclusion}

Considering the simple supply and demand mechanism in the model (the use of cereals as a proxy for demand and area changes), the likely range of global cropland simulated in this study ranged from 893 to 2380 Mha in 2100 . This was consistent with the range reported in the literature of 930-
2670 Mha in 2100 , although slightly skewed to the lower end of this range. This shows that uncertainties in input assumptions are equally important for output ranges as differences in the model structure and that the entire uncertainty of global cropland development is probably even larger if these sources of uncertainties are combined. Considering the uncertainties in input assumptions, we found that the deep uncertainties reflected in assumptions for the socio-economic scenarios contributed most to the total magnitude of the projected cropland range. The uncertainties in scenario interpretation widened the total projected future cropland range and led to overlap in the simulated cropland areas for three out of five scenarios. Cropland futures where the output PDFs did not overlap with other scenarios were found for the SSP1 scenario projections and the SSP3 scenarios, whereas the SSP2, SSP4 and SSP5 scenarios were found to have large areas of overlap. This was partly due to the compensating dynamics of drivers, e.g. strong yield development and increase in consumption in the SSP5 scenario, but also due to the larger uncertainties in scenarios with contrasting challenges for mitigation and adaptation (i.e. SSP5 and SSP4 scenarios). Uncertainties in population projections, technological change and cropland degradation were found to be the most important for uncertainty in global cropland projections, while uncertainties in consumption levels and production levels were found to be less important. When taking account of the uncertainty ranges at the $95 \%$ confidence interval across all scenarios, there were fewer differences between the scenarios, i.e. there is overlap at some level of probability in all global cropland projections, except for projections based on SSP3. This leads us to conclude that very different worlds can result in very similar cropland futures on the aggregated global scale as long as they share low to medium population development.

\section{Data availability}

Simulation results presented in Figs. 3 and 4 are available for download from doi:10.18161/plum.201610. 


\section{Appendix A: Model development}

\section{A1 Changes compared to previous PLUM version}

In comparison to the version described in Engström et al. (2016), several minor alterations (Table A1) and one larger alteration were made to the model. The larger alteration relates to the representation of the yield development in PLUM, which is explained below. Assumptions are also made within PLUM about the scenario dependency of the availability of potential arable land (residualNV), reflecting different environmental policies in the SSPs.

\section{A2 Yield development in PLUM}

The global parameter 6_technology describes the change in trend of technological development. The parameter 6_investment characterizes how much yield increases as a function of GDP per capita. The parameter 6_distribution describes how agricultural management practices are assumed to be transferred across and within countries. For example, in a scenario with an emphasis on human development, it is assumed that the distribution of technologies would be more efficient and thus the yield gap would decrease more rapidly, compared to a scenario that only emphasizes investment in technology but not its distribution. Here we assumed that 6 _distribution is negatively correlated to the percentage of rural population (derived from the urban share projections from 2010 to 2100 NCAR, v9_130115; SSP Database, 2015) on the basis that a larger share of rural population implies more small-scale farming with simple technologies and lower yields. Additionally, the variables in Table A2 were added during the implementation of LPJ-GUESS-driven yield development in PLUM.

Cereal yield cerealYieldC is calculated in the following way:

cerealYieldC $=$ if cerealYield $\times$ shareYield $_{\mathrm{i}}>$ cerealYieldFAO $\mathrm{i} \times$ boundaryShare then cerealYield $\times$ shareYield $_{\mathrm{i}}$ else cerealYieldFAO $\mathrm{i} \times$ boundaryShare.

To avoid yields decreasing to $50 \%$ (corresponding to default boundaryShare of 0.5 ) or less than the initial (i) FAO value

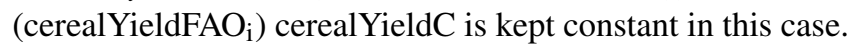
The LPJ-GUESS-based calculated yield (cerealYield) is normalized with FAOSTAT cereal yield by multiplying with shareYield $_{i}$.

shareYield $_{\mathrm{i}}=$ cerealYieldFAO $_{\mathrm{i}} /$ yieldA $_{\mathrm{i}}$
cerealYield $_{t}$ is calculated as follows:

cerealYield $_{t}=\operatorname{yieldP}_{t} \times\left(1-\right.$ yieldGap $\left._{t}\right)$.

yieldGap $_{t}$ is calculated as follows:

yieldGap $_{t}=1-\left(\right.$ yieldA $_{t} \times k_{t} /\left(\right.$ yieldP $\left.\left._{t}\right)\right)$.

The function $k_{t}$ determines how much of actual yield vs. potential yield is produced during time:

If $q<0.98$, then

$k_{t}=\operatorname{kmax}_{t} \times\left(1-\left(h_{t} \times q_{t}\right)\right)$

else $k_{t}=\operatorname{kmax}_{t}\left(1-\left(h_{t} \times 0.98\right)\right.$.

The maximum value of $\operatorname{kmax}_{t}$ is

$\operatorname{kmax}_{t}=\operatorname{yieldP}_{t} /$ yieldA $_{t}$.

The function $h_{t}$ :

$h_{t}=\left(1-\left(1 / \operatorname{kmax}_{t}\right)\right) / q_{\mathrm{i}}$.

The function $q_{t}$ describes the impact of investments in technology and distribution of technology on yields. Investments in technology are here assumed to be dependent on income growth (GDP per capita), and distribution of technology is assumed to be related to the share of urban population in total population.

$q_{t}=\exp \left(-\right.$ technol $_{t}-$ investment $_{t} \times \mathrm{gdpPc}_{t}+$ distribution $_{t} \times\left(100-\right.$ urbanShare $\left.\left._{t}\right)\right)$

The functions technol ${ }_{t}$, distribution and investment $_{t}$ allow the change in the initial factors which were found by regression analysis based on statistical analysis of data for the year 1995-2005:

technol $_{t}=0.77+6 \_$technology $/ 100 \times$ time ()

investment $_{t}=(1.80+6$ _investment $/ 100 \times \operatorname{time}()) \times 10^{-5}$

distribution $_{t}=\left(2.55-6 \_\right.$distribution $\left./ 100 \times \operatorname{time}()\right) \times 10^{-3}$.

The scenario-dependent input parameters 6_technology, 6_investment and 6_distribution were parameterized guided by their standard deviations of $0.125,0.650 \times 10^{-5}$ and $1.000 \times 10^{-3}$ respectively (see Table B1). 
Table A1. PLUM development, affected variable, rationale for development and implemented development.

\begin{tabular}{|c|c|}
\hline Variable & Rationale for development \\
\hline $\begin{array}{l}\text { Food conversion } \\
\text { ratio (fcr) }\end{array}$ & $\begin{array}{l}\text { The fcr for beef, pork, sheep and chicken were input } \\
\text { parameters that were changed based on assumptions re- } \\
\text { lated to technological development. The input param- } \\
\text { eter fcr improvement }(\text { fcrImp) was changed simultane- } \\
\text { ously for the same reason. This was a doubling of the } \\
\text { effect of technological change on the efficiency of ani- } \\
\text { mal production. }\end{array}$ \\
\hline
\end{tabular}

Expected In the variable expPro, it is calculated how much more production cereals should be supplied by each country in the next (expPro)
Development

The for input parameters were removed (but kept in PLUM as initial values), and fcrImp is the only scenario variable that changes animal production efficiency.

The expPro now includes the following rules:

- Global cereal surplus - exporting countries are assumed to decrease their production by the minimum of either their domestic surplus or their share of the global surplus (including demand created by overProdRate).

- Global cereal surplus, importing countries - no change is assumed; only if cereal self-sufficiency should be increased, are countries assumed to increase production by their domestic deficit.

- Global cereal deficit - exporting countries are assumed to increase their production by their share of the global deficit (including demand created by overProdRate).

- Global cereal deficit - importing countries are assumed to increase their production by the maximum of either their domestic deficit or the share of the global deficit (including demand created by overProdRate).

\section{Expected} production (expPro) and residual natural vegetation (residualNV)
Previously there was no restriction regarding how much more cereals an area of land can be expected to produce based on the availability of land with natural vegetation (grassland and forest) in the countries. This was implemented here, using estimates of per country potential arable land (FAO, 2000).

\section{Cropland degradation (croplandDeg)}

Previously it was assumed that degraded cropland would be removed from the cropland used (that is, cerealland), but it seems closer to reality that croplandDeg should influence the production capacity of the cerealland used.
A scenario-dependent share of land with natural vegetation (specified in the input parameter residual natural vegetation (residualNV; \% of potential arable land potArableLand (1000 ha, derived from FAO, 2000)) restricts the expPro for countries. If a country has less residual natural vegetation (defined as all ((forest + grassland) / potArableLand) $\times 100$, or if ((forest + grassland) $/$ potArableLand $) \times 100<$ residual potential arable land (resPotAL $=(($ potArableLand - cerealland - restCropland) $/$ potArableLand) $\times 100$ ), then resPotAL) left than resiudalNV), then no expPro is assumed for this country. Instead this country's expPro is divided among all other exporting countries.

croplandDeg changes the production of cereals with the following equation: cerealProduction $=$ cerealland $\times$ cerealYield - cerealland $\times$ cerealYield $\times$ croplandDeg $/ 100 \times$ time () .

So the value of croplandDeg, that is, the share of lost production, is achieved at the end of the simulation period (after 100 years).

Cropland was estimated assuming that the share of cereals and other crops (oil crops, pulses, roots and tubers, vegetables and fruits) will remain constant in the future.

One additional stock, restCropland, is added, with flows from grassland and forest. restCropland is cropland cerealland. The flow from grassland and forest equal (landconversion/shareOfCropland - landconversion) 
Table A2. Yield-related variables in PLUM.

\begin{tabular}{lll}
\hline Variable type & Variable name & Source \\
\hline Initial value & cerealYieldFAO $_{\mathrm{i}}$ & FAOSTAT, 2015 \\
Initial value & yieldA $_{\mathrm{i}}$ & First year of yieldA_t (currently year 2000) \\
Initial value & $q_{\mathrm{i}}$ & q_t at time 0, i.e. year 2000 in this version \\
Time series & yieldP $_{t}$ & LPJ-GUESS, potential yield \\
Time series & yieldA $_{t}$ & LPJ-GUESS, actual yield \\
Time series & gdpPc $_{t}$ & Income growth, GDP per capita, SSP data \\
Time series & urbanShare $_{t}$ & Share of population living in urban areas, SSP data \\
Model parameter & boundaryShare & Share of cerealYieldFAO that yield can decrease \\
& & to as a minimum \\
\hline
\end{tabular}




\section{Appendix B: Input to the conditional probabilistic approach}

\section{B1 Extended SSP narratives}

\section{B1.1 SSP1: sustainability - taking the green road}

Key themes: Cooperative countries, environmentally friendly, functioning markets

Facilitating governance and institutional structures, cooperative countries, environmentally conscious societies and decreased inequalities contribute in this SSP to the progress towards a sustainable world, including lower population growth. Due to effective international institutions and good information flow between markets, governments and farmers and functioning global markets, agricultural areas are decreased rapidly in case of food overproduction. Countries rely on regional trade, and attempts are made to keep food stocks low in order to be resource efficient. The conversion of natural land to new cropland is well regulated in most countries to avoid substantial deforestation and biodiversity loss. Investments in agriculture and agricultural research stay high in high-income countries, and local, contextdependent agricultural best-management practices (including non-conventional practices, e.g., no tillage) are implemented in most countries. The investment in technology continues to result in more efficient animal protein production. An additional important factor for globally increasing yields is the technology transfer between countries and income levels. Equity and education are important in this scenario and contribute to yield improvements as well. The awareness for resource efficiency also decreases food waste and the consumption of refined products, which leads to a decreasing cereal consumption. The environmental awareness of consumers leads to a slowing down and an eventual decrease in the consumption of dairy and meat products. However, low-income countries moderately increase their animal product consumption until they reach consumption levels that are common among western countries. Environmental degradation slows down and the status of land improves, thanks to increasing implementation of holistic and sustainable management and afforestation programs.

\section{B1.2 SSP2: middle of the road}

Key themes: Business as usual

In SSP2 trends observed during recent decades continue, including some reductions in resource intensity, but mostly large inequalities between countries and economies remain. Technological development is moderate and preliminary, concentrated in high-income countries. Due to limited technology transfer, low-income countries do not benefit from advances in agricultural management and yields remain rather low. Agricultural markets are partially functioning and globally connected, but trade barriers are only reduced slowly. Some countries with limited access to global markets focus more strongly on increased domestic production and self-sufficiency. In general food stocks are held at moderate levels and the abandonment of cereal land remains unregulated. For new cropland generation, high-income countries follow existing regulations, while in some low-income countries with rich natural resources unregulated deforestation for cropland generation continuous to be a problem. Environmental degradation continues at historical rates, as no serious efforts are made to achieve large-scale sustainable land management. Additionally the continuing increasing demand for animal products contributes to expansion and intensification of agriculture with some negative environmental impacts.

\section{B1.3 SSP3: regional rivalry - a rocky road}

Key themes: World regions, security of regions, no progress in technologies

In the fragmented world, regional blocks form, with little international cooperation and protectionist policies of regions as a result. This leads to little reduction of land intensity, low technological development and generally slow economic growth but high population growth. However, in some areas wealth moderately increases, and so does technological development. The increasing efforts of regions to be more food self-sufficient reduce agricultural trade and increase the food overproduction within regions to ensure sufficient food supply in case of regional harvest shortcomings. Consequently, agricultural area is only abandoned at a very slow pace, even if a region is food sufficient. At the same time, weak governance and institutional structures do not provide any strong regulations reducing the conversion of natural land to cropland. Forests and natural grasslands are converted into cropland at faster rates to ensure regional food security. Food consumption, and in particular the consumption of animal products, continues to increase in most regions but at a slower pace for low-income countries. The increased demand for food and the non-regulated land use change result in serious environmental degradation.

\section{B1.4 SSP4: inequality - a road divided}

Key themes: The few wealthy control, the rest struggles

This world is characterized by high inequality, within and across countries, as well as between economies. In all countries, including low-income countries, few very privileged people steer all political, economic and industrial activities. This includes agriculture, which is strongly divided into highly industrialized large-scale monoculture agriculture steered by the privileged and small-scale farming performed by a large group of poor people. Investments in agricultural development of the industrial agriculture are large, but no technology transfer occurs to the small-scale farming, and here yields remain low. If the industrialized agricultural production is not profitable, cropland is abandoned at fast rates, while at the same time natural land is converted at fast 
rates to new cropland without considering environmental and social effects. The absence of sustainability regulations leads to serious environmental degradation, affecting the poor and making them even more vulnerable. The global food trade is dominated by the industrial agricultural businesses with very limited access for small-scale farmers. Small-scale farmers therefore rely more on self-sufficient agricultural systems. While the privileged society increases its consumption of animal products, the large group of poor people cannot afford large increases in meat and dairy consumption. The overall demand for food production does therefore not proportionally increase with the high population growth, as most of the world's people cannot afford an expensive diet in times of economic uncertainty.

\section{B1.5 SSP5: fossil-fuelled development - taking the highway}

Keywords: Resource intensive, no compromises to gain material wealth

In this world economic, resource-intensive development is prioritized, and while this leads to eradication of extreme poverty, it comes at environmental costs. Developing countries are pushed in their development, and soon all countries share a resource-intensive lifestyle, including high levels of animal product consumption. The high demand for these and other agricultural products is fulfilled by highly engineered agricultural systems. Investment into agricultural technology is very high. Increasing agricultural specialization of countries is common too; however, it is often connected to very resource-intensive production, both in terms of water and fertilizers. Agricultural area also expands into natural areas at faster rates if necessary. Solutions to environmental problems do not tackle the problem's roots, but only its symptoms. However, the global food market functions well and keeps the total food stock decrease slow.

\section{B2 Examples of rationales for changes in trend and uncertainty levels for PLUM input parameters conditional on SSPS}

An example of the importance of being explicit about baseline trends is the following: in SSP5 the very strong trend of technology improving agricultural management (Table 1; SSP5; technology: +++ ) is, when compared to the generally strong baseline trend of technology $(++)$, not considered extreme. To illustrate this approach further, consider for instance the scenario element "globalization" from Table 2, which we assumed will influence, jointly with scenario elements "international trade" and "agriculture", the input parameter that guides the level of food production in the model. If we take SSP3, a degree of de-globalization and enhanced regional security is assumed to be taking place in future (O'Neill et al., 2016). Consistent with a world where the trend of globalization is reversed and regional security is important, we assumed for SSP3 that production levels would be higher $(+++$, Table 1$)$ compared to the current trend in order to ensure the satisfaction of demand internally. The opposite is true for SSP1, where "globalization" leads to "connected markets, regional production" (O'Neill et al., 2016). We assumed that production levels would be lower (--; Table 1) than present-day levels since food would be distributed more efficiently around the globe. The reduction of production levels would also decrease food waste, which is consistent with SSP1's "policy orientation" towards sustainable development.

\section{B3 Quantitative values for input parameters}

For each scenario and each input parameter, quantitative values were derived by sampling from Table B1 based on the scenario and input parameter's qualitative notions in Table 1.

This matrix (Table B1) was populated by first placing the (baseline) mean value (Engström et al., 2016) based on the quantitatively estimated baseline trend within the matrix. Secondly, we identified minimum and maximum values for each input parameter, based on statistical analysis of historic data or the authors' judgement as described in Engström et al. (2016). Thirdly, these values informed the extremes $(---$ and +++$)$, and the entries between the extremes and the baseline mean values were filled with evenly interpolated values. The quantitative values for the qualitative uncertainty levels low, medium and high were informed by variability in historic data. We assumed the historic standard deviations to be generally high because data were analysed over a time period (1961-1990) where substantial changes in consumption and production patterns led to high heterogeneity in the data (Alexander et al., 2015). We used the historic standard deviation for the high uncertainty value. The medium and the low uncertainty values are two thirds and one thirds of the high uncertainty level respectively (Table B1).

The values for a change in trends (mean) and uncertainty value (standard deviation) were used to create the probability distribution function for each input parameter. We assumed a normal distribution for all input parameters, except parameters 7-9. These parameters are maximum values, and it seems more plausible that they are equally likely (uniform distribution). For population, we truncated the distribution because the very low population projections of SSP1 (peak of global population size in 2050-2055 at 8.5 billion, a decline in total population size to 6.9 billion in 2100) requires a very stringent decline in fertility rates, and even for SSP1 with a high focus on education (the most important driver for changes in fertility rates), it seems very unlikely to us that the projections will be lower by -1 standard deviation. With the reversed argumentation, we truncated the upper bound of the PDF for population for SSP3, as SSP3 population projections are derived at a very high total population size of 12.6 billion people in 2100 . 
Table B1. Matrix with quantitative values for changes in trend from --- to +++ (mean values) and the uncertainty levels low, medium and high (1 standard deviation, SD). Values are based on analysis of historical data, except that values with ${ }^{\mathrm{a}}$ were estimated by the author (see Engström et al., 2016). Superscript b indicates that values are maximum values rather than standard deviations. Values in bold are baseline values, corresponding to the baseline trend in Table 1.

\begin{tabular}{|c|c|c|c|c|c|c|c|c|c|c|c|}
\hline \multirow[t]{2}{*}{ No. } & \multirow[t]{2}{*}{ Input parameter (unit) } & \multicolumn{7}{|c|}{ Change in trend, mean values } & \multicolumn{3}{|c|}{ Uncertainty, $1 \mathrm{SD}$} \\
\hline & & --- & -- & - & 0 & + & ++ & +++ & Low & Medium & High \\
\hline 0 & gdp Var $(\%)$ & \multirow{2}{*}{\multicolumn{7}{|c|}{ country-level time series for each SSP }} & \multirow{2}{*}{\multicolumn{3}{|c|}{$\begin{array}{l}\text { calculated based on other } \\
\text { projections; see Table } 1\end{array}$}} \\
\hline 0 & pop $\operatorname{Var}(\%)$ & & & & & & & & & & \\
\hline 1 & overProdRate (1/time) & -0.004 & -0.003 & -0.002 & -0.001 & 0.000 & 0.001 & 0.002 & 0.0002 & 0.0004 & 0.0006 \\
\hline 2 & cerealVar $(1 /$ time $)$ & -0.003 & -0.002 & -0.001 & 0.000 & 0.001 & 0.002 & 0.003 & 0.0002 & 0.0004 & 0.0006 \\
\hline 3 & meat 1 (kg meat per capita/log(GDP per capita)) & -10.0 & -5.0 & 0.0 & 5.0 & 10.0 & 15.0 & 20.0 & 2.0 & 4.0 & 6.0 \\
\hline 3 & meat $2(\mathrm{~kg}$ meat per capita/log(GDP per capita)) & -6.0 & -3.0 & 1.0 & 3.0 & 5.0 & 10.0 & 15.0 & 1.0 & 2.0 & 3.0 \\
\hline 3 & meat 3 (kg meat per capita/log(GDP per capita)) & -5.0 & 0.0 & 5.0 & 10.0 & 15.0 & 20.0 & 25.0 & 1.0 & 2.0 & 3.0 \\
\hline 3 & meat 4 (kg meat per capita/log(GDP per capita)) & -2.5 & 0.0 & 2.5 & $\mathbf{5 . 0}$ & 10.0 & 15.0 & 20.0 & 1.0 & 2.0 & 3.0 \\
\hline 4 & milk 1 (kg milk per capita/log(GDP per capita)) & -10.0 & -5.0 & 0.0 & 5.0 & 10.0 & 15.0 & 20.0 & 2.0 & 4.0 & 6.0 \\
\hline 4 & milk 2 (kg milk per capita/log(GDP per capita)) & -4.0 & -2.0 & 0.0 & 2.0 & 6.0 & 10.0 & 14.0 & 1.0 & 2.0 & 3.0 \\
\hline 4 & milk 3 (kg milk per capita/log(GDP per capita)) & -5.0 & 0.0 & 5.0 & 10.0 & 15.0 & 20.0 & 25.0 & 2.0 & 4.0 & 6.0 \\
\hline 4 & milk 4 (kg milk per capita/log(GDP per capita)) & -2.5 & 0.0 & 2.5 & 5.0 & 10.0 & 15.0 & 20.0 & 2.0 & 4.0 & 6.0 \\
\hline 5 & fcrImp $p^{\mathrm{a}}(1 /$ time $)$ & -0.002 & -0.001 & 0.000 & 0.001 & 0.002 & 0.003 & 0.004 & 0.0003 & 0.0006 & 0.0009 \\
\hline 6 & distribution (1/time) & -1.00 & -0.66 & -0.33 & 0.00 & $\mathbf{0 . 3 3}$ & 0.66 & 1.00 & 0.15 & 0.30 & 0.45 \\
\hline 6 & technology $(1 /$ time $)$ & -0.125 & -0.080 & -0.040 & 0.000 & 0.040 & 0.080 & 0.125 & 0.030 & 0.060 & 0.090 \\
\hline 6 & investment $(1 /$ GDP per capita $\times$ time $)$ & -0.65 & -0.43 & -0.21 & 0.00 & 0.21 & 0.43 & 0.65 & 0.10 & 0.20 & 0.30 \\
\hline 7 & abandon $C L^{\mathrm{b}}$ (unitless) & 0.010 & 0.015 & 0.020 & 0.023 & 0.040 & 0.055 & 0.070 & 0.003 & 0.006 & 0.009 \\
\hline 7 & abandon $C L \_D^{\mathrm{b}}$ (unitless) & 0.010 & 0.011 & 0.013 & 0.015 & 0.025 & 0.035 & 0.050 & 0.003 & 0.006 & 0.009 \\
\hline 8 & new $C L^{\mathrm{b}}$ (unitless) & 0.010 & 0.011 & 0.013 & 0.015 & 0.250 & 0.035 & 0.048 & 0.003 & 0.006 & 0.009 \\
\hline 8 & new $C L \_D^{\mathrm{b}}$ (unitless) & 0.010 & 0.018 & 0.025 & 0.029 & 0.035 & 0.040 & 0.045 & 0.003 & 0.006 & 0.009 \\
\hline 9 & newCLs ${ }^{\mathrm{b}}$ (unitless) & 0.000 & 0.000 & 0.000 & 0.000 & 0.015 & 0.030 & 0.048 & 0.003 & 0.006 & 0.009 \\
\hline 9 & newCLs_D $D^{\mathrm{b}}$ (unitless) & 0.010 & 0.018 & 0.025 & 0.029 & 0.035 & 0.040 & 0.045 & 0.003 & 0.006 & 0.009 \\
\hline 10 & grassForest $^{\mathrm{a}}$ (unitless) & 0.50 & 0.50 & 0.50 & 0.50 & 0.50 & 0.50 & 0.50 & 0.03 & 0.06 & 0.09 \\
\hline 11 & residualNV $V^{\mathrm{a}}(\%)$ & 4.0 & 6.0 & 8.0 & 10.0 & 12.0 & 14.0 & 16.0 & 1.0 & 2.0 & 3.0 \\
\hline 12 & croplandDeg $^{\mathrm{a}}$ (1/time) & 0.04 & 0.06 & 0.08 & 0.10 & 0.12 & 0.14 & 0.16 & 0.03 & 0.06 & 0.09 \\
\hline 12 & forestDeg ${ }^{\mathrm{a}}(1 /$ time $)$ & 0.004 & 0.006 & 0.008 & 0.010 & 0.012 & 0.014 & 0.016 & 0.003 & 0.006 & 0.009 \\
\hline
\end{tabular}


Appendix C: Additional output

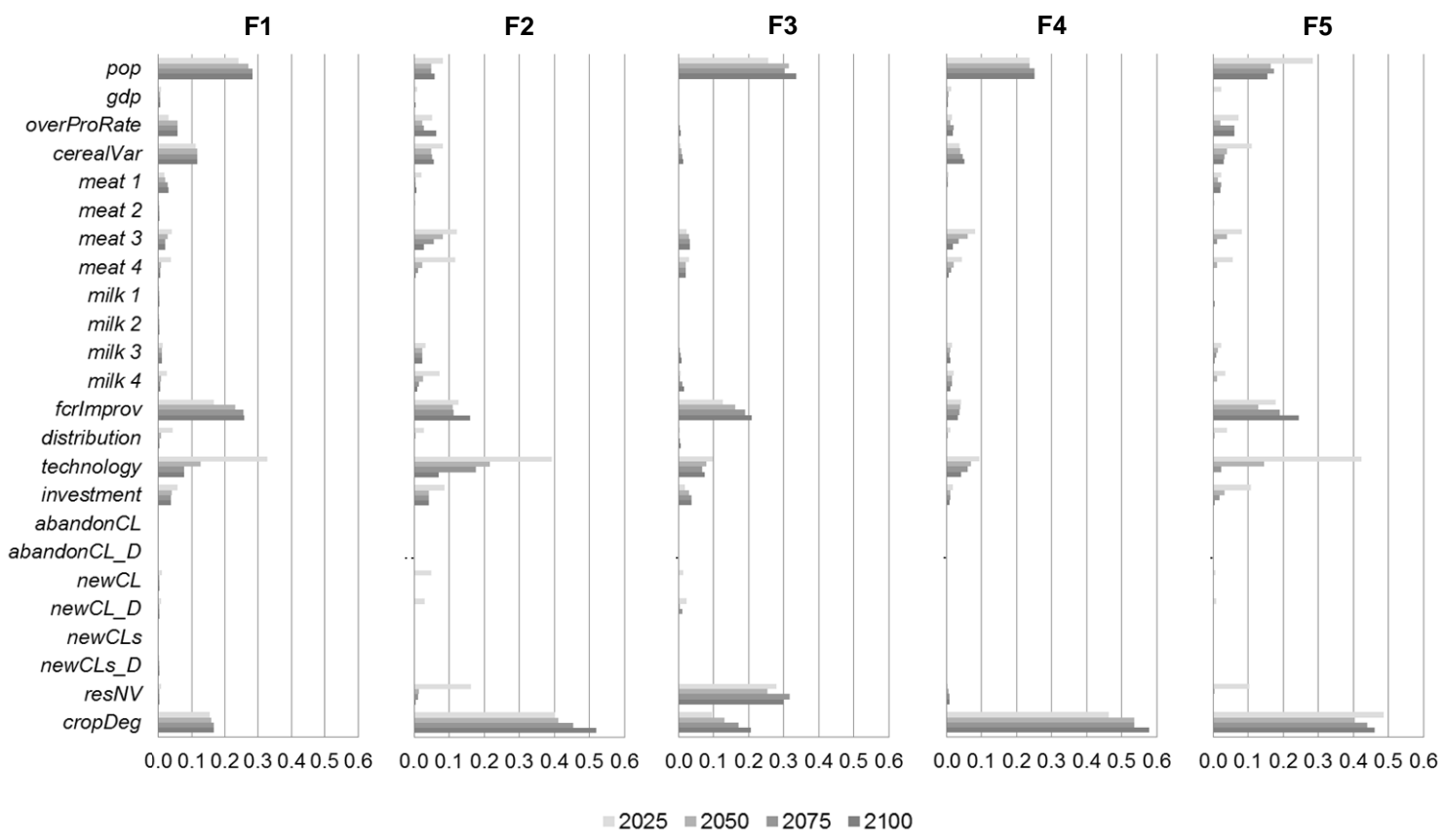

Figure C1. Total importance of cropland to uncertainty of input parameters conditional on SSPs. 
Author contributions. Kerstin Engström, Mark D. A. Rounsevell, Almut Arneth, Stefan Olin and Dave Murray-Rust designed the study. Kerstin Engström and Sara Brogaard assessed the uncertainties for global PLUM parameters. Detlef P. van Vuuren, Kerstin Engström, Mark D. A. Rounsevell and Peter Alexander estimated the qualitative and quantitative probabilities of the scenario matrix. Kerstin Engström and Stefan Olin developed the model code and performed the simulations. Kerstin Engström prepared the paper with contributions from all co-authors.

Acknowledgements. This study was carried out under the Formas Strong Research Environment grant to Almut Arneth, Land use today and tomorrow (LUsTT; dnr: 211-2009-1682). The authors would also like to thank J. Lindström for discussion of statistical methods for the yield sampling. Mark D. A. Rounsevell, Detlef P. van Vuuren and Almut Arneth acknowledge support by the FP7 project LUC4C (grant no. 603542).

Edited by: J. Dyke

Reviewed by: two anonymous referees

\section{References}

Ahlström, A., Smith, B., Lindström, J., Rummukainen, M., and Uvo, C. B.: GCM characteristics explain the majority of uncertainty in projected 21 st century terrestrial ecosystem carbon balance, Biogeosciences, 10, 1517-1528, doi:10.5194/bg-10-15172013, 2013.

Alexander, P., Rounsevell, M. D. A., Dislich, C., Dodson, J. R., Engström, K., and Moran, D.: Drivers for global agricultural land use change: The nexus of diet, population, yield and bioenergy, Global Environ. Chang., 35, 138-147, 2015.

Alexander, P., Prestele, R., Verburg, P. H., Arneth, A., Fujimori, S., Hasegawa, T., Jain, A. K., Meiyappan, P., Dunford, R., Harrison, P. A., Brown, C., Holzhauer, S., Dendoncker, N., Steinbuks, J., Lenton, T., Powell, T., Sands, R. D., Kyle, P., Wise, M. A., Doelman, J., Stehfest, E., Schaldach, R., Jacobs-Crisioni, C., Lavalle, C., van Meijl, H., Tabeau, A., Humpenöder, F., Popp, A., Engström, K., Butler, A., Liu, J., and Rounsevell, M.: Assessing uncertainties in future land cover projections, Glob. Change Biol., online first, doi:10.1111/gcb.13447, 2016.

Amiro, B. D., MacPherson, J. I., and Desjardins, R. L.: BOREAS flight measurements of forest-fire effects on carbon dioxide and energy fluxes, Agr. Forest Meteorol., 96, 199-208, 1999.

Brown, C., Brown, E., Murray-Rust, D., Cojocaru, G., Savin, C., and Rounsevell, M.: Analysing uncertainties in climate change impact assessment across sectors and scenarios, Climatic Change, 128, 293-306, 2014.

Clarke, L., Jiang, K., Akimoto, K., Babiker, M., Blanford, G., Fisher-Vanden, K., Hourcade, J.-C., Krey, V., Kriegler, E., Löschel, A., McCollum, D., Paltsev, S., Rose, S., Shukla, P. R., Tavoni, M., van der Zwaan, B. C. C., and van Vuuren, D. P.: Assessing Transformation Pathways, in: Climate Change 2014: Mitigation of Climate Change. Contribution of Working Group III to the Fifth Assessment Report of the Intergovernmental Panel on Climate Change, edited by: Edenhofer, O., PichsMadruga, R., Sokona, Y., Farahani, E., Kadner, S., Seyboth, K.,
Adler, A., Baum, I., Brunner, S., Eickemeier, P., Kriemann, B., Savolainen, J., Schlömer, S., von Stechow, C., Zwickel, T., and Minx, J. C., Cambridge University Press, Cambridge, UK and New York, NY, USA, 2014.

Collins, M., Knutti, R., Arblaster, J., Dufresne, J.-L., Fichefet, T., Friedlingstein, P., Gao, X., Gutowski, W. J., Johns, T., Krinner, G., Shongwe, M., Tebaldi, C., Weaver, A. J., and Wehner, M.: Long-term Climate Change: Projections, Commitments and Irreversibility, in: Climate Change 2013: The Physical Science Basis. Contribution of Working Group I to the Fifth Assessment Report of the Intergovernmental Panel on Climate Change, edited by: Stocker, T. F., Qin, D., Plattner, G.-K., Tignor, M., Allen, S. K., Boschung, J., Nauels, A., Xia, Y., Bex, V., and Midgley, P. M., Cambridge University Press, Cambridge, UK and New York, NY, USA, 2013

Collins, W. J., Bellouin, N., Doutriaux-Boucher, M., Gedney, N., Halloran, P., Hinton, T., Hughes, J., Jones, C. D., Joshi, M., Liddicoat, S., Martin, G., O’Connor, F., Rae, J., Senior, C., Sitch, S., Totterdell, I., Wiltshire, A., and Woodward, S.: Development and evaluation of an Earth-System model - HadGEM2, Geosci. Model Dev., 4, 1051-1075, doi:10.5194/gmd-4-10512011, 2011.

Dufresne, J. L., Foujols, M. A., Denvil, S., Caubel, A., Marti, O., Aumont, O., Balkanski, Y., Bekki, S., Bellenger, H., Benshila, R., Bony, S., Bopp, L., Braconnot, P., Brockmann, P., Cadule, P., Cheruy, F., Codron, F., Cozic, A., Cugnet, D., de Noblet, N., Duvel, J. P., Ethé, C., Fairhead, L., Fichefet, T., Flavoni, S., Friedlingstein, P., Grandpeix, J. Y., Guez, L., Guilyardi, E., Hauglustaine, D., Hourdin, F., Idelkadi, A., Ghattas, J., Joussaume, S., Kageyama, M., Krinner, G., Labetoulle, S., Lahellec, A., Lefebvre, M. P., Lefevre, F., Levy, C., Li, Z. X., Lloyd, J., Lott, F., Madec, G., Mancip, M., Marchand, M., Masson, S., Meurdesoif, Y., Mignot, J., Musat, I., Parouty, S., Polcher, J., Rio, C., Schulz, M., Swingedouw, D., Szopa, S., Talandier, C., Terray, P., Viovy, N., and Vuichard, N.: Climate change projections using the IPSL-CM5 Earth System Model: from CMIP3 to CMIP5, Clim. Dynam., 40, 2123-2165, 2013.

Dunne, J. P., John, J. G., Shevliakova, E., Stouffer, R. J., Krasting, J. P., Malyshev, S. L., Milly, P. C. D., Sentman, L. T., Adcroft, A. J., Cooke, W., Dunne, K. A., Griffies, S. M., Hallberg, R. W., Harrison, M. J., Levy, H., Wittenberg, A. T., Phillips, P. J., and Zadeh, N.: GFDL's ESM2 Global Coupled Climate-Carbon Earth System Models. Part II: Carbon System Formulation and Baseline Simulation Characteristics, J. Climate, 26, 2247-2267, 2013.

Ebi, K. L., Hallegatte, S., Kram, T., Arnell, N. W., Carter, T. R., Edmonds, J., Kriegler, E., Mathur, R., O’Neill, B. C., Riahi, K., Winkler, H., Van Vuuren, D. P., and Zwickel, T.: A new scenario framework for climate change research: background, process, and future directions, Climatic Change, 122, 363-372, 2014.

Engström, K., Rounsevell, M. D. A., Murray-Rust, D., Hardacre, C., Alexander, P., Cui, X., Palmer, P. I., and Arneth, A.: Applying Occam's razor to global agricultural land use change, Environ. Modell. Softw., 75, 212-229, 2016.

FAO: World Soil Resources Reports: Land resource potential and constraints at regional and country levles. Food and Agriculture Organization of the United Nations, Rome, Italy, 2000.

FAOSTAT: Food and Agriculture Organization of the United Nations Statistics Division, http://faostat3.fao.org/, last access: 10 December 2015. 
Fischer, R. A., Byerlee, D., and Edmeades, G. O.: Crop yields and global food security: will yield increase continue to feed the world? ACIAR Monograph No. 158. Australian Centre for International Agricultural Research, Canberra, Australia, 2014.

Hurtt, G. C., Chini, L. P., Frolking, S., Betts, R. A., Feddema, J., Fischer, G., Fisk, J. P., Hibbard, K., Houghton, R. A., Janetos, A., Jones, C. D., Kindermann, G., Kinoshita, T., Klein Goldewijk, K., Riahi, K., Shevliakova, E., Smith, S., Stehfest, E., Thomson, A., Thornton, P., Vuuren, D. P., and Wang, Y. P.: Harmonization of land-use scenarios for the period 1500-2100: 600 years of global gridded annual land-use transitions, wood harvest, and resulting secondary lands, Climatic Change, 109, 117-161, 2011.

Iversen, T., Bentsen, M., Bethke, I., Debernard, J. B., Kirkevåg, A., Seland, Ø., Drange, H., Kristjansson, J. E., Medhaug, I., Sand, M., and Seierstad, I. A.: The Norwegian Earth System Model, NorESM1-M - Part 2: Climate response and scenario projections, Geosci. Model Dev., 6, 389-415, doi:10.5194/gmd-6-3892013, 2013.

Jansen, M. J. W.: Analysis of variance designs for model output, Comput. Phys. Commun., 117, 35-43, 1999.

KC, S. and Lutz, W.: The human core of the shared socioeconomic pathways: Population scenarios by age, sex and level of education for all countries to 2100, Global Environ. Chang., doi:10.1016/j.gloenvcha.2014.06.004, in press, 2016.

Knutti, R. and Sedlacek, J.: Robustness and uncertainties in the new CMIP5 climate model projections, Nature Climate Change, 3, 369-37, 2013.

Kriegler, E., Edmonds, J., Hallegatte, S., Ebi, K. L., Kram, T., Riahi, K., Winkler, H., and van Vuuren, D. P.: A new scenario framework for climate change research: the concept of shared climate policy assumptions, Climatic Change, 122, 401-414, 2014.

Lilburne, L. and Tarantola, S.: Sensitivity analysis of spatial models, Int. J. Geogr. Inf. Sci., 23, 151-168, 2009.

Lindeskog, M., Arneth, A., Bondeau, A., Waha, K., Seaquist, J., Olin, S., and Smith, B.: Implications of accounting for land use in simulations of ecosystem carbon cycling in Africa, Earth Syst. Dynam., 4, 385-407, doi:10.5194/esd-4-385-2013, 2013.

Lutz, W. and KC, S.: Dimensions of global population projections: what do we know about future population trends and structures?, Philos. T. Roy. Soc. B, 365, 2779-2791, 2010.

Mastrandrea, M. D., Field, C. B., Stocker, T. F., Edenhofer, O., Ebi, K. L., Frame, D. J., Held, H., Kriegler, E., Mach, K. J., Matschoss, P. R., Plattner, G. K., Yohe, G. W., and Zwiers, F. W.: Guidance Note for Lead Authors of the IPCC Fifth Assessment Report on Consistent Treatment of Uncertainties, Intergovernmental Panel on Climate Change (IPCC), available at: https://www.ipcc.ch/pdf/ supporting-material/uncertainty-guidance-note.pdf (last access: 5 October 2016), 2010.

Mueller, N. D., Gerber, J. S., Johnston, M., Ray, D. K., Ramankutty, N., and Foley, J. A.: Closing yield gaps through nutrient and water management, Nature, 490, 254-257, 2012.

O’Neill, B. C.: Population Scenarios Based on Probabilistic Projections: An Application for the Millennium Ecosystem Assessment, Popul. Environ., 26, 229-254, 2005.

O’Neill, B. C., Kriegler, E., Riahi, K., Ebi, K. L., Hallegatte, S., Carter, T. R., Mathur, R., and van Vuuren, D. P.: A new scenario framework for climate change research: the concept of shared socioeconomic pathways, Climatic Change, 122, 387-400, 2013.
O’Neill, B. C., Kriegler, E., Ebi, K. L., Kemp-Benedict, E., Riahi, K., Rothman, D. S., van Ruijven, B. J., van Vuuren, D. P., Birkmann, J., Kok, K., Levy, M., and Solecki, W.: The roads ahead: Narratives for shared socioeconomic pathways describing world futures in the 21st century, Global Environ. Chang., doi:10.1016/j.gloenvcha.2015.01.004, in press, 2016.

Pereira, H. M., Navarro, L. M., and Martins, I. S.: Global Biodiversity Change: The Bad, the Good, and the Unknown, Annu. Rev. Env. Resour., 37, 25-50, 2012.

Portmann, F. T., Siebert, S., and Döll, P.: MIRCA2000-Global monthly irrigated and rainfed crop areas around the year 2000: A new high-resolution data set for agricultural and hydrological modeling, Global Biogeochem. Cy., 24, 1-24, 2010.

Prestele, R., Alexander, P., Rounsevell, M., Arneth, A., Calvin, K., Doelman, J., Eitelberg, D., Engström, K., Fujimori, S., Hasegawa, T., Havlik, P., Humpenöder, F., Jain, A. K., Krisztin, T., Kyle, P., Meiyappan, P., Popp, A., Sands, R. D., Schaldach, R., Schüngel, J., Stehfest, E., Tabeau, A., van Meijl, H., van Vliet, J., and Verburg, P. H.: Hotspots of uncertainty in land use and land cover change projections: a global scale model comparison, Glob. Change Biol., doi:10.1111/gcb.13337, 2016.

Pujol, G., Iooss, B., and Janon, A.: Global Sensitivity Analysis of Model Outputs, available at: http://cran.r-project.org/package= sensitivity, last access: 23 February 2015.

Rosenzweig, C., Jones, J. W., Hatfield, J. L., Ruane, A. C., Boote, K. J., Thorburn, P., Antle, J. M., Nelson, G. C., Porter, C., Janssen, S., Asseng, S., Basso, B., Ewert, F., Wallach, D., Baigorria, G., and Winter, J. M.: The Agricultural Model Intercomparison and Improvement Project (AgMIP): Protocols and pilot studies, Agr. Forest Meteorol., 170, 166-182, 2013.

Rounsevell, M. D. A. and Metzger, M. J.: Developing qualitative scenario storylines for environmental change assessment, Wiley Interdisciplinary Reviews: Climate Change, 1, 606-619, 2010.

Saltelli, A., Ratto, M., Andres, T., Campolongo, F., Cariboni, J., Gatelli, D., Saisana, M., and Tarantola, S.: Global sensitivity analysis: the primer, Wiley Online Library, West Sussex, UK, ISBN: 978-0-470-05997-5, 2008.

Saltelli, A., Annoni, P., Azzini, I., Campolongo, F., Ratto, M., and Tarantola, S.: Variance based sensitivity analysis of model output. Design and estimator for the total sensitivity index, Comput. Phys. Commun., 181, 259-270, 2010.

Schmitz, C., van Meijl, H., Kyle, P., Nelson, G. C., Fujimori, S., Gurgel, A., Havlik, P., Heyhoe, E., d'Croz, D. M., Popp, A., Sands, R., Tabeau, A., van der Mensbrugghe, D., von Lampe, M., Wise, M., Blanc, E., Hasegawa, T., Kavallari, A., and Valin, H.: Land-use change trajectories up to 2050: insights from a global agro-economic model comparison, Agr. Econ., 45, 69-84, 2014.

Smith, B., Perentice, I. C., and Sykes, M. T.: Representation of vegetation dynamics in the modelling of terrestrial ecosystems: comparing two contrasting approaches within European climate space, Global Ecol. Biogeogr., 10, 621-637, 2001.

Smith, P., Gregory, P. J., van Vuuren, D., Obersteiner, M., Havlik, P., Rounsevell, M., Woods, J., Stehfest, E., and Bellarby, J.: Competition for land, Philos. T. Roy. Soc. B, 365, 2941-2957, 2010.

SSP Database: SspDb_country_data_2012-05-11, available at: https://secure.iiasa.ac.at/web-apps/ene/SspDb/, last access: 6 February 2013. 
SSP Database: SspDb_country_data_2013-06-12, available at: https://secure.iiasa.ac.at/web-apps/ene/SspDb/, last access: 2 December 2015.

van Vuuren, D. P. and Carter, T. R.: Climate and socio-economic scenarios for climate change research and assessment: reconciling the new with the old, Climatic Change, 122, 415-429, 2014. van Vuuren, D. P., de Vries, B., Beusen, A., and Heuberger, P. S. C.: Conditional probabilistic estimates of 21 st century greenhouse gas emissions based on the storylines of the IPCC-SRES scenarios, Global Environ. Chang., 18, 635-654, 2008.

van Vuuren, D. P., Edmonds, J., Kainuma, M., Riahi, K., Thomson, A., Hibbard, K., Hurtt, G. C., Kram, T., Krey, V., Lamarque, J.F., Masui, T., Meinshausen, M., Nakicenovic, N., Smith, S. J., and Rose, S. K.: The representative concentration pathways: an overview, Climatic Change, 109, 5-31, 2011.

van Vuuren, D. P., Riahi, K., Moss, R., Edmonds, J., Thomson, A., Nakicenovic, N., Kram, T., Berkhout, F., Swart, R., Janetos, A., Rose, S. K., and Arnell, N.: A proposal for a new scenario framework to support research and assessment in different climate research communities, Global Environ. Chang., 22, 21-35, 2012.

van Vuuren, D. P., Kriegler, E., O’Neill, B. C., Ebi, K. L., Riahi, K., Carter, T. R., Edmonds, J., Hallegatte, S., Kram, T., Mathur, R., and Winkler, H.: A new scenario framework for Climate Change Research: scenario matrix architecture, Climatic Change, 122, 373-386, 2014.
Watanabe, M., Chikira, M., Imada, Y., and Kimoto, M.: Convective Control of ENSO Simulated in MIROC, J. Climate, 24, 543-562, 2011.

Wiebe, K., Lotze-Campen, H., Sands, R., Tabeau, A., van der Mensbrugghe, D., Biewald, A., Bodirsky, B., Islam, S., Kavallari, A., Mason-D’Croz, D., Müller, C., Popp, A., Robertson, R., Robinson, S., van Meijl, H., and Willenbockel, D.: Climate change impacts on agriculture in 2050 under a range of plausible socioeconomic and emissions scenarios, Environ. Res. Lett., 10, 085010, doi:10.1088/1748-9326/10/8/085010, 2015.

World Bank: The World Bank DATA, available at: http://data. worldbank.org/, last access: 25 August 2015.

Zaehle, S., Bondeau, A., Carter, T. R., Cramer, W., Erhard, M., Prentice, I. C., Reginster, I., Rounsevell, M. D. A., Sitch, S., Smith, B., Smith, P. C., and Sykes, M.: Projected Changes in Terrestrial Carbon Storage in Europe under Climate and Landuse Change, 1990-2100, Ecosystems, 10, 380-401, 2007.

Zika, M. and Erb, K.-H.: The global loss of net primary production resulting from human-induced soil degradation in drylands, Ecolo. Econ., 69, 310-318, 2009. 